\title{
LOS DERECHOS SOCIALES Y SU APLICACIÓN EN LA GUARDIA CIVIL
}

ANTONIOTRONCOSO REIGADA

ProfesorTitular de Derecho Constitucional. 
SUMARIO

I. Los DERECHOS SOCIALES. 1. La aparición de los derechos sociales: del Estado liberal de derecho al Estado social y democrático de derecho. a) El Estado liberal de derecho. b) El Estado democrático de derecho. c) El Estado social y democrático de derecho. 2. Manifestaciones históricas del Estado social. 3. Los derechos sociales en la Constitución Española de 1978. a) La vertiente prestacional de los derechos de libertad. b) Los derechos sociales como derechos fundamentales. c) Los principios rectores de la política

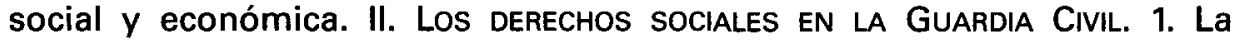
Guardia Civil como institución. Su carácter civil y militar. Las funciones de la Guardia Civil. 2. Los derechos sociales de los miembros de la Guardia Civil. a) El derecho a una remuneración suficiente. b) El derecho a la salud y a la seguridad en el trabajo. c) El derecho a la vivienda: protección a la familia, parejas de hecho y prohibición de discriminación. d) El derecho a la conciliación de la vida familiar y laboral. 3. Algunas reflexiones finales. 


\title{
LOS DERECHOS SOCIALES Y SU APLICACIÓN EN LA GUARDIA CIVIL
}

\author{
POR \\ ANTONIOTRONCOSO REIGADA \\ Profesor Titular de Derecho Constitucional.
}

I. LOS DERECHOS SOCIALES.

1. LA APARICIÓN DE LOS DERECHOS SOCIALES:

DEL ESTADO LIBERAL DE DERECHO AL ESTADO SOCIAL Y DEMOCRÁTICO DE DERECHO.

a) El Estado liberal de derecho.

El Estado liberal, que se desarrolla durante finales del siglo XVIII y durante el siglo $\mathrm{XIX}$, se caracteriza y se diferencia del Estado absoluto en que no se fundamenta en la voluntad del soberano sino en la supremacía de la Ley y en la garantía de la libertad para los individuos. En el modelo constitucional del Estado liberal, era tarea de la Constitución limitar el poder de la Corona y garantizar a los ciudadanos un ámbito de libertades. Así, los poderes públicos se someten a unas normas jurídicas que el Estado mismo se da. El sometimiento a este mandato general y abstracto, que habilita a las autoridades para actuar y establece límites, facilita el control por parte de un poder judicial independiente y supone un elemento esencial de racionalización del poder. Este concepto, que la dogmática alemana califica como Estado de derecho - Rechtstaat - es común a las distintas tradiciones jurídicas y da vida a distintos principios jurídicos: la rule of law, la reserva de ley, o el principio de legalidad. El reconocimiento de 
la libertad de los individuos no implica la desaparición del poder público sino su legitimación nueva a través del derecho. Las libertades - reconocidas en las Constituciones liberales- demandan que su regulación se efectúe a través de la Ley'.

El Estado liberal era un Estado constituido sobre el principio de libertad, no referido a los grupos sociales sino a los individuos aisladamente, considerados libres frente al Estado. Los derechos reconocidos en las Constituciones, con una clara dimensión individual, jugaban un papel importante en la garantía de la libertad, al ser configurados como derechos de defensa frente a los poderes públicos, que exigían a éstos abstenerse de intervenir. Estos derechos, presentes en las Constituciones liberales y que se han mantenido en la actualidad, eran la libertad ideológica y religiosa, la libertad personal y ausencia de detenciones, la inviolabilidad del domicilio y el secreto de las comunicaciones, la libertad de expresión y comunicación, la libertad de residencia y de circulación, la tutela judicial, el principio de legalidad penal, el derecho a la vida, el derecho al honor y a la intimidad. El Estado liberal suponía, por tanto, el respeto a la libertad en sentido formal y una racionalización en el ejercicio del poder.

A la vez, otro principio característico del constitucionalismo liberal es el de igualdad formal o igualdad legal. Para el liberalismo burgués, la igualdad significaba la abolición de los privilegios contenidos en las normas. En el Antiguo Régimen, a cada estamento le correspondía distintas leyes y distintos Tribunales. El Estado liberal de derecho afirmó: por una parte, el carácter general y abstracto de la Ley, que debe ser para todos y no para un grupo de ciudadanos; por otra, la universalidad en sus efectos en relación con sus destinatarios, es decir, la igualdad como derecho en la aplicación de la Ley, como idéntica posición de los destinatarios de la Ley en cuanto a su aplicación por los Tribunales y la Administración. Una Ley para todos y todos iguales ante la Ley, lo que prohíbe las decisiones judiciales y administrativas arbitrarias, irracionales o puramente subjetivas ${ }^{2}$.

1 Cfr. L. LÓPEZ GuerRA, Introducción al Derecho Constitucional, Tirant lo blanch, Madrid, 1994, págs. 101-125; J. PÉrez RoYo, Estado de Derecho ( $D^{\circ}$ Constitucional), AA.VV, Enciclopedia Jurídica Básica, II, Civitas, Madrid, págs. 2906-2909; J. DE ESTEBAN, Tratado de Derecho Constitucional, l, 2001, Madrid; M. ARAGÓN, "Constitución y Estado de Derecho", España: un presente para el futuro, II, Madrid, 1984; A. TORRERS DEL MORAL, Principios de Derecho Constitucional Español, Atomo, Madrid, 1985, págs. 19-23; E. Alvarez Conde, "El Estado liberal como Estado de Derecho", Curso de Derecho Constitucional, I, $2^{\circ}$ ed, Tecnos, Madrid, 1996, págs. 93-107.

2 Cfr. F. Rubio LloRente, "Rango de ley, fuerza de ley, valor de ley", y "Principio de legalidad", en id., La forma del poder, cit. págs. 319-332; A. Garrorena Morales, El lugar de la Ley en la Constitución Española, CEC, Madrid, 1980. 
Es la burguesía la que anima las revoluciones del XVIII y las Constituciones liberales, $y$, por tanto, el Estado que nace de ellas está hecho a la medida de las necesidades de la burguesía y de su sistema económico. El Estado salvaguarda la propiedad privada y la libertad de comercio e industria, bases de la sociedad burguesa ${ }^{3}$, y se limita a desarrollar aquellas funciones externas necesarias para el funcionamiento del modelo capitalista de producción, esto es, al mecanismo monetario, a establecer las normas generales que debían regular el tráfico jurídico privado, a fijar instancias de resolución de conflictos y a ciertas infraestructuras. El proceso económico está despolitizado y desestatalizado, siendo el Estado una institución complementaria del carácter autorregulador del mercado 4 . En la concepción liberal, los problemas sociales se resolverían por sí mismos a partir del libre juego de las fuerzas de mercado. Así, si se confiaban a las fuerzas sociales en concurrencia amplios márgenes de libre configuración, la armonía social vendría por añadidura. Se estaba dispuesto a pagar el precio del mantenimiento de situaciones sociales gravosas, porque parecía más importante la libertad, al tiempo que la igualdad quedaba como una mera proclamación formal ${ }^{5}$. La idea de un Estado gendarme, que se limita a mantener el orden y la seguridad imprescindibles para el ejercicio de los derechos individuales y cuya principal obligación es la preservación de la libertad y los derechos patrimoniales, se muestra claramente en la Constitución francesa de 1791 y en la Constitución de Cádiz de $1812^{6}$.

La Administración que sirve al Estado liberal de Derecho es una Administración centralizada. El Estado liberal no era compatible con el corporativismo y el gremialismo del Antiguo Régimen y con el particularismo de villas y ciudades, que dificultaban las libertades económicas y de comercio que propugnaba la burguesía. El modelo de Administración centralizada nace así después de la Revolución francesa, como obra de

3 Un análisis del Derecho de propiedad, desde la concepción del Estado liberal de Derecho se puede ver en J. M. LASALLE, John Locke y los fundamentos modernos de la propiedad, Dykinson, Madrid, 2001, págs. 405-412.

4 Cfr. G. ARiño, Economía y Estado, Madrid, 1993.

5 Cfr. K. HeSSE, "Constitución y Derecho Constitucional", en, BENDA, MAIHOFER, VOGEL, HESSE, HIEDE Manual de Derecho Constitucional, (ed. Preparada por A. López Pina), Marcial Pons-IVAP, 1996, pág. 11; K, HESSE, Grundzüge des Verfassungsrechts der Bundesrepublik Deutschland, 18, ed, C. F. Müller, Heidelberg, 1991, págs. 3-18.

6 Cfr. S. Muñoz MaChado, Servicio público y mercado. Los fundamentos, Civitas, Madrid, 1998, págs. 45-71. 
Napoleón que trasladó a la Administración civil las técnicas de la organización militar?.

De la etapa del Estado liberal de derecho, el constitucionalismo ha heredado conceptos de carácter formal o técnico como el carácter normativo de la Constitución 8 , la diferenciación entre poder constituyente y poder constituido, la división de poderes, la distribución horizontal de competencias, la vinculación de los poderes públicos a la Ley y al derecho, el principio de legalidad, la seguridad jurídica, la prohibición de arbitrariedad, la separación Estado-sociedad, el reconocimiento de derechos y su garantía jurisdiccional, la independencia de los jueces o el principio del juez ordinario 9 .

\section{b) El Estado democrático de derecho.}

Frente a la tendencia elitista del primer constitucionalismo, que sometía el Estado al derecho y separaba los poderes, pero que no establecía la legitimidad democrática del poder y de la ley, el constitucionalismo a partir de la segunda mitad del siglo XIX va introduciendo la idea de democracia, que está vinculada al concepto de soberanía popular, es decir, al derecho del pueblo a gobernarse a si mismo mediante la participación en las instituciones. Si las Constituciones de la primera mitad del siglo XIX definían como forma de organización política concreta la monarquía constitucional basada en la doble legitimidad monárquica y representativa, progresivamente las Constituciones afirman la legitimidad democrática del poder. Durante los siglos XIX y XX los derechos de participación experimentan una evolución paralela al principio democrático y a la universalización del sufragio, que de ser censitario pasa a ser universal, se extiende a las mujeres y se reduce la mayoria de edad para votar. Si el Estado libe-

7 Cfr. E. GaRcia DE ENTERRIA, Revolución francesa y Administración contemporánea, Cívitas, Madrid, 1994.

8 Cfr. E. Garcia de ENTERRÍA, La Constitución como norma y el Tribunal Constitucional, $3^{\circ}$ ed, Cívitas, Madrid, 1983, págs. 39-62; R. L. BLANCO VALDÉs, El valor de la Constitución, Alianza Editorial, 1998.

9 Cfr. S. Muñoz MACHADO, La reserva de jurisdicción, La Ley, Madrid, 1989, págs. 11-21; M. A. Aparicio Pérez, "Prólogo", a D. SIMON, La independencia del juez, Ariel, Barcelona, 1985, págs. V-XXIV; idem, El status del Poder judicial en el constitucionalismo español (1808-1936), Universidad de Barcelona, 1995; L. M. Dízz PiCazo Régimen constitucional del Poder Judicial, Cívitas, Madrid, 1991, págs. $69-79$ y 102-106; J. L. ReQueJo PAGÉs, Jurisdicción e independencia judicial, CEC, Madrid, 1989, págs. 161-193. 
ral era consecuencia de un contrato social de una parte minoritaria de la sociedad, impuesto a la mayoría, que ha sido excluida a través de la restricción del sufragio, el Estado democrático trata de ser un poder público representativo de toda la sociedad ${ }^{10}$.

El Estado liberal es un presupuesto no sólo histórico sino también jurídico del Estado democrático y ambos están íntimamente vinculados. El propio concepto de libertad del constitucionalismo liberal albergaba en su germen una dimensión activa o positiva: comprendía la participación de los ciudadanos en la adopción de decisiones de la comunidad. Es necesario el reconocimiento efectivo de la libertad personal para el ejercicio de los derechos políticos. A la vez, para que las libertades personales lo sean auténticamente, es necesario un previo debate político y la vigencia del principio democrático en las instituciones representativas que regulen $y$ desarrollen estas libertades. No obstante, la regla de la mayoría no impide que un grupo importante de los ciudadanos se vean privados de su libertad. El carácter normativo de la Constitución y de los derechos allí recogidos es la garantía de que la voluntad popular no va a llegar a cercenar los derechos del individuo.

Si el centralismo es la característica de la Administración que sirve el Estado liberal de Derecho, el Estado democrático con la extensión del sufragio y de las libertades políticas favoreció la reivindicación política de autogobierno de los territorios y condujo a una mayor descentralización territorial del poder $y$ a un progresivo reconocimiento de autonomía a las Regiones y a los Municipios, que acerca la Administración a los ciudadanos e introduce un incremento de la legitimación democrática de los poderes públicos, a través de más órganos e instituciones representativas. No obstante, como ya hemos señalado en otra ocasión, mientras que la autonomía local es una garantía institucional de carácter administrativo, consecuencia del principio democrático y de la fragmentación del poder, el federalismo refleja una autonomía política - no meramente administrativa- y está vinculada también al respeto a los derechos colectivos de los pueblos $^{11}$.

10 Cfr. A. Garrorena Morales, "Estado democrático ( $D^{\circ}$ Constitucional), AA.VW, Enciclopedia Jurídica Básica, II, Civitas, Madrid, págs. 2917-2923; M. ARAGON, Constitución y democracia, Madrid, 1989, págs. 25-34.

11 Cfr. A. Troncoso ReIgada, “La Autonomía Local: garantía institucional, desarrollo político y dificultades prácticas", Estudios de Derecho Constitucional. Homenaje al Profesor Dr. D. Joaquín Garcia Morillo, Tirant lo blanch, Valencia, 2001, págs. 571576. 
El constitucionalismo democrático ha introducido en los textos constitucionales conceptos como la soberanía popular, el pluralismo político y social, el principio mayoritario, los derechos políticos - de asociación, de reunión, de manifestación, de petición, de participación política directamente o por medio de representantes-. El Estado democrático frente a los modelos autoritarios ha exigido no sólo la participación politica en las instituciones representativas sino también la participación social de los ciudadanos en la Administración y sobre todo la descentralización territorial y la desconcentración administrativa.

c) El Estado social y democrático de derecho.

El efectivo ejercicio de los derechos de libertad del Estado de Derecho y de participación política del Estado democrático sólo cobra sentido si hay unas condiciones materiales previas para todos los ciudadanos, que aseguren un mínimo vital12. Como has señalado LÓPEZ GUERRA, "difícilmente podrá predicarse el derecho a la inviolabilidad de domicilio del que no tiene casa, o el derecho a la libertad personal del que depende de otros para su mera subsistencian 13 .

Las revoluciones industriales de los siglos XIX y XX llevaron al abandono de las zonas agrarias y a la creación de un proletariado urbano, que vivia en muy malas condiciones. Aflora así la llamada "cuestión social», que origina el surgimiento de los movimientos sindicales obreros y de los partidos políticos de masas -laboristas, socialistas, comunistas-, que ya no son una simple agrupación de miembros del Parlamento sino organizaciones sociales enraizadas en los sectores sociales más desfavorecidos y que tienen como común identidad el conflicto de clases ${ }^{14}$. Si el constitucionalismo liberal luchó contra el absolutismo estatal, la arbitrariedad del poder, la supervivencia de elementos feudales y el proteccionismo mercantil, y el constitucionalismo democrático por los derechos políticos y la universalización del sufragio, los movimientos sociales reclaman ahora una mayor justicia social

12 Cfr. J. De Esteban, “La función transformadora de las Constituciones occidentales", en AAV, Constitución y Economía. La ordenación del sistema económico en las Constituciones occidentales, Madrid, 1977, págs. 149-160; E. DIAZ, Estado de Derecho y sociedad democrática, Madrid,1981.

13 Cfr. L. LOPEZ GUERRA, Introducción al Derecho Constitucional, Tirant lo blanch, Madrid, 1994, págs. 159-170.

14 Cfr. G. Amato y A. Barbera, Manuale di diritto pubblico, $4^{\mathrm{a}}$ ed. Bologna, 1994, pág. 61. 
que evite la explotación de las clases más desfavorecidas ${ }^{15}$. Si las revoluciones liberales se habian limitado a sustituir una clase por otra, los movimientos sociales hacen que el sistema político se convierta en un Estado pluriclasse, ya que no sólo una única clase social sino todas ellas tienen acceso al poder ${ }^{16}$. La amenaza de las revoluciones sociales fuerza a la burguesía a tratar de paliar las desigualdades sociales a través de procedimientos reformistas y no violentos. El aumento demográfico unido a la propia revolución industrial transforma la geografía: la sociedad occidental deja de ser preferentemente agraria y ganadera y se produce el fenómeno de la urbanización que puebla las ciudades. Ya no era posible el autoabastecimiento sino se produce una mayor interdependencia. Esto obliga al Estado a asegurar la procura existencial de las complejas sociedades urbanas $e$ industriales, que antes se cubría de manera natural17.

Los principios que sustentaban el Estado liberal de Derecho son puestos en entredicho. El bien común no resulta por generación espontánea del mercado y de las fuerzas sociales. Al contrario, en cualquier sociedad, especialmente en la sociedad industrializada, los intereses de los grupos sociales chocan entre sí. El libre juego de las fuerzas sociales contribuye a la hegemonía de los más fuertes económica y socialmente sobre los. más débiles. La capacidad personal y el esfuerzo no bastan para garantizar un progreso equilibrado de los distintos sectores sociales. No hay armonía social $y$ esto es puesto de manifiesto reiteradamente por los planteamientos revolucionarios del proletariado. El principio de igualdad del Constitucionalismo liberal, entendido como igualdad formal, no suprime las desigualdades sociales. Puede ser que los ciudadanos sean iguales ante la Ley - sólo ante ésta-, pero no lo son en realidad. Es necesario alcanzar una mayor igualación en los niveles de vida, es decir, una igualdad material, una igualdad real y efectiva.

15 Una interesante reflexión sobre la extensión de la idea de democracia, sobre el concepto de democracia social como indicador de movimientos sociales y sobre movimiento constitucional, cuestión social y derechos sociales se puede ver en J. J. Gomes Canotilho, Direito Constitucional, Almedina, Coimbra, 1996, págs. 407-409, donde se resume el debate de la doctrina alemana.

16 Al surgimiento del Estado de pluralidad de clases se refiere M. S. GIANNINI, Derecho Administrativo, MAP, Madrid, 1991, págs. 76-78.

17 Cfr. L. Martín Retortillo Baquer, "La configuración jurídica de la Administración pública y el concepto de "Daseinvorsorge»", RAP, núm. 38, 1962, págs. 35-65; J. A. Santamaría Pastor, Principios de Derecho Administrativo, $3^{\circ}$ ed., CEURA, Madrid, págs. 69-74. 
La garantía de una existencia material digna para todos los ciudadanos depende considerablemente de la intervención del Estado. La libertad de los ciudadanos no estriba sólo en una liberación de los poderes públicos. La auténtica libertad y autonomía de la persona depende mucho de una serie de condiciones que no están a disposición de todos individuos. La dotación de estas condiciones es una clara tarea del Estado, un Estado que debe ser ya del aseguramiento social. Sólo los poderes públicos pueden remover obstáculos y discriminaciones sociales y favorecer una sociedad más justa. Corresponde al Estado hacer prevalecer los intereses generales de la sociedad sobre los de determinados grupos sociales, a través de una regulación que haga recaer cargas económicas sobre los más favorecidos y redistribuya y facilite la participación de los sectores más débiles ${ }^{18}$.

Esta función no la podía cumplir el modelo del antiguo Estado liberal, constituido en una salvaguarda del entramado institucional de la sociedad burguesa y de la propiedad privada. El Estado liberal no se inmiscuía en la realidad social y únicamente velaba por el funcionamiento de las normas generales que regulaban las relaciones recíprocas entre sujetos económicos. El respeto al Derecho privado era compatible con la mayor de las injusticias ya que los problemas materiales no eran planteables desde perspectivas exclusivamente formales. El modelo del Estado liberal, al separar el Estado y la sociedad y concebir los derechos como libertades frente al Estado, que exigían la abstención de éste, no dejaban al Estado ningún instrumento para participar activamente en el progreso social. El Estado liberal como Estado gendarme era incapaz de afrontar los nuevos problemas 19 .

Se hace necesario modificar la doctrina del Estado liberal por otra que, sin entrar en contradicción con los intereses de la burguesía, rompa con la doctrina de la separación entre el Estado y la sociedad y atribuya al Estado la capacidad de dar respuesta a la cuestión social. La regulación constitucional del Estado y de sus funciones no se debía limitar a un sistema de técnicas formales sino que debe configurar un Estado con un contenido material y con un compromiso con los valores. De esta forma, el Estado abandona su posición de neutralidad formal - que no real- dentro del conflicto de intereses sociales $y$ asume un papel activo en la composi-

18 Cfr. E. BENDA, "Estado Social de Derecho", en BENDA, MAIHOFER, VOGEL, HESSE, HIEDE, Manual de Derecho Constitucional, cit. págs. 487-559, esp. págs. 490 y 545.

19 La evolución del reformismo conservador al Estado del bienestar ha sido analizado por A. GaRRorena Morales, El Estado Español como Estado social y democrático de Derecho, cit. págs 37-41. 
ción de los intereses y en la resolución de los problemas sociales, desde unos objetivos de justicia y de progresiva igualdad de las clases sociales ${ }^{20}$. El Estado pasa de ser un Estado gendarme, que no intervenía en nada en el libre juego de las fuerzas sociales- a tener una voluntad de corregir activamente las desigualdades $y$ de intentar que la igualdad formal se acerque de manera progresiva a la igualdad real y a la consecución del bien común.

Lógicamente, dentro de la superación del Estado liberal, hay concepciones -e ideologías - dentro del Estado social más y menos ambiciosas. Desde una posición de mínimos, para FORSTHOFF, el Estado se ve obligado a prestar unos servicios que garantice la procura existencial daseinvorsorge $-y$ a ejercer una función subsidiaria para que el espacio vital efectivo y el espacio vital dominado se vayan identificando 21 . Desde una posición más generosa - HESSE -, los derechos de las personas y el Estado pasan de excluirse recíprocamente a encontrarse en una situación de dependencia22. Es decir, la efectividad de los derechos fundamentales está encomendada al Estado y esto requiere un Estado fuerte, capaz de garantizar determinadas prestaciones sociales. Así, los poderes públicos asumen la responsabilidad de conformar el orden social para permitir a todos los ciudadanos un cierto nivel de bienestar, el acceso a la educación y la cobertura de los riesgos vitales. El Estado ya no es un enemigo potencial de la libertad sino su defensor y protector. No se trata de limitar el poder el Estado, sino de garantizar efectivamente la libertad y una vida digna, que no se alcanzan ya de la abstención del Estado o de un principio de exclusión sino a través de una activa intervención de los poderes públicos. El Estado incide, de esta forma, en la conformación de la sociedad, mediante la participación en el aseguramiento de determinados bienes y servicios. Se supera así la antigua posición de que el Estado solo interviene de manera caritativa y se dirige básicamente a la conservación del orden público. No se trata de que los principios y los derechos de las Constituciones liberales - libertad, igualdad, democracia - sean negados, sino que se llevan a su más plena realización. Se trata de que la libertad no sea sólo abstracta sino disfrutada por todos, con independencia de su

20 Cfr. V. ONIDA, “L'organizzazione costituzionale”, en G. AMATo y A. BARBERA, Manuale di diritto pubblico, cit. págs. 90-92.

21 Cfr. E. Forsthoff, "Concepto y esencia del Estado social de Derecho", en W. Abendroth, E. Forsthoff y K. Doehring, El Estado social, CEC, Madrid, 1986.

22 Cfr. K, HESSE, Grundzüge des Verfassungsrechts der Bundesrepublik Deutschland, cit. págs. 85-88. Cfr. K, HeSSE, "Constitución y Derecho Constitucional", y. "Significado de los derechos fundamentales", en Benda; MaIHOfER, Vogel, Hesse, Hiede, Manual de Derecho Constitucional, cit. págs. 11-12 y 95, respectivamente. 
situación social y que la igualdad no sea sólo una igualdad de tratamiento sino un efectivo equilibrio de posiciones sociales.

El Estado trata de jugar un papel activo en la economía, ya que es visto como un instrumento, no sólo para transformar la sociedad y para corregir la desigualdad, sino también como motor de la economía y generador de crecimiento económico. Si en el Estado liberal, la disciplina constitucional de la economía se reducía a la garantía de la propiedad y de la libertad de comercio, ahora los poderes públicos convierten la economía en un instrumento transformador de la sociedad. Manteniéndose dentro de los principios más generales de la economía de mercado, el Estado desarrollará una intensa regulación de la actividad económica, e incluso asumirá la función empresarial, superando los paradigmas del liberalismo clásico ${ }^{23}$.

El concepto de Estado Social como categoría dogmática nace en la doctrina alemana. HELLER acuñó la expresión Estado Social como representativo de las nuevas funciones de los poderes públicos, que no se preocupan sólo por asegurar la libertad de los ciudadanos, sino también por su situación económica, reconociendo ciertos derechos sociales 24 . La burguesía alemana, consciente del significado $y$ de la gravedad de los procesos revolucionarios europeos del siglo $\mathrm{XIX}$, reacciona de forma conservadora y trata de transformar el Estado formal de Derecho en uno material, sin abandonar los elementos fundamentales de su propia concepción. El Estado social trata de ser un término medio entre el Estado liberal y la ruptura socialista-marxista, manteniendo los principios esenciales del sistema capitalista. El Estado social sigue siendo un Estado de Derecho y, por tanto, un Estado garantista del individuo frente al poder, pero también un Estado comprometido con la promoción del bienestar en la sociedad. Las características básicas del Estado social de Derecho son las mismas que la del Estado liberal, aunque las funciones del Estado varíen sustancialmente, pasando de un Estado abstencionista a un Estado intervensionista y redistribuidor de recursos 25 .

23 Cfr. J. Corcuera y M. A. Garcia Herrera, Derecho y Economía en el Estado social, Madrid, 1988.

24 Cfr. H. HeLleR, “Rechtsstaat oder Diktatur", 1929, en Gesammelte Schriften, II, Leiden, 1971; idem, Teoria del Estado, Fondo de Cultura Económica, México, 1992, págs. 217-234. Cfr. E. FORSTHOFF, El Estado de la sociedad industrial, IEP, Madrid, 1975, págs. 120 122, y Tratado de Derecho Administrativo, IEP, Madrid, 1958, págs. 62-63 y 473-480.

25 Cfr. J. Pérez Royo, Estado social de Derecho ( $D^{\circ}$ Constitucional), AA.VV, Enciclopedia Juridica Básica, II, Civitas, Madrid, págs. 2924-2926. En todo caso, para Pérez Royo, utilizar el término social para definir un determinado tipo de Estado y de Derecho es literalmente un sin sentido, porque el Estado y el Derecho son dos fenómenos que no pueden ser más que sociales. No obstante, esta fórmula trata de sintetizar la diferencia entre el Estado a lo largo del siglo XIX del Estado democrático a partir de la crisis de 1917. 
El constitucionalismo social se inicia en el período de entreguerras con la Constitución mexicana de Querétano de 1917, la alemana de Weimar de 1919 o la española de la II República de 1931, que tratan de ser un pacto entre las clases medias y los partidos obreros 26 . Pero fueron los textos constitucionales posteriores a la Segunda Guerra Mundial -Constitución francesa de 1946, Constitución italiana de 1947- los que comienzan a atribuir garantía jurisdiccional a algunos derechos sociales, convirtiendo en derecho positivo muchas aspiraciones sociales. La expresión Estado Social -sozialer Rechtsstaat- aparece por vez primera en las Constituciones de los Länder alemanes y en el art. 20 de la Ley Fundamental de Bonn de 194927.

La Constitución Española de 1978 señala en su artículo 1.1 que "España se constituye en un Estado social y democrático de Derecho". Esta expresión -España es el sujeto de la oración-, norma de apertura semejante al artítulo 1 de la Constitución española de la II República - «España es una República democrática de trabajadores de toda clase" - y al art. 1 de la Constitución italiana de 1948 - «Italia es una República democrática basada en el trabajon - supone una materialización del poder constituyente $y$ una ruptura con el modelo de Estado franquista. La expresión representa una fórmula de síntesis que define nuestro Estado con tres características: Estado de derecho, Estado democrático y Estado social. De esta forma, España como nación opta por un tipo de organización jurídico-política que se denomina Estado social y democrático de Derecho. Los preceptos constitucionales de carácter social de nuestra Constitución -igualdad real y efectiva, derechos sociales, principios rectores de la política social y económica, Constitución económica - condensan la experiencia en el ámbito del'i Estado social de los países occidentales ${ }^{28}$. Las tres notas definitorias del Estado se corresponde con los valores superiores que a continuación se propugnan: el Estado de Derecho, que contrapone el Estado con la sociedad, y afirma una esfera de libertad de los individuos; el Estado democrático, que exige la soberanía popular y el pluralismo político; y el Estado social, que atribuye al Estado una intervención dirigida a la corrección de las desigualdades y a la consecución de una igualdad real29.

26 Cfr. F. Tena Ramirez, Derecho Constitucional Mexicano, Porrúa, México, 1981; J. F. Ruiz Massieu y D. VAlades, Nuevo Derecho Constitucional Mexicano, Porrúa, México, 1983.

27 Cfr. K, HESSE, Grundzüge des Verfassungsrechts der Bundesrepublik Deutschland, cit. págs. 85-88; T. MAUNZ y R. ZIPPELIUS, Deutsches Staatsrecht, C.H. Beck, München, 1994, págs. 60-62 131-133 y 162.

28 Cfr. E. Alvarez Conde, "El Estado social y democrático de Derecho", Curso de Derecho Constitucional, I, $2^{\circ}$ ed, Tecnos, Madrid, 1996, págs. 108-131.

29 Cfr. L. PAREJo, Estado social y Administración pública. Los postulados constitucionales de la reforma administrativa, Cívitas, Madrid, 1983. 
La expresión "Estado social y democrático de derecho» es fruto de la evolución ya descrita y asume la interdependencia del constitucionalismo liberal, democrático y social. El Estado - en un determinado grado de evolución - es un presupuesto del Derecho constitucional30. Cada una de las transformaciones experimentadas por el Estado de derecho significa un claro progreso respecto de la estructura anterior 31 . El constitucionalismo transforma el modelo de Estado, al reconocer derechos fundamentales $y$ atribuir nuevas tareas a los poderes públicos. El constitucionalismo que define al Estado como social y democrático de derecho incorpora a éste el elemento socioeconómico propio de la convivencia política occidenta|32. El Estado social presupone un sistema político democrático. A la vez, quien está llamado a tomar decisiones políticas deben estar en una situación de libertad real que le sitúe en una situación de poder elegir. El Estado social y democrático de Derecho es resultado de un pacto constitucional durante la transición entre posiciones políticas y clases sociales distintas.

Es necesaria una interpretación total y armónica de la fórmula Estado social y democrático de derecho, que integre las tres definiciones del Estado, interpretando cada uno de sus rasgos en función de los demás y sin contradecir el conjunto ${ }^{33}$. Esta interpretación integral debe asumir el carácter dialéctico de la fórmula, que es resultado de un proceso histórico que va desde las revoluciones burguesas de finales del XVIII al constitucionalismo más moderno, y que asume en sus últimas manifestaciones los propios límites del Estado del bienestar ${ }^{34}$. El Estado Español es cada una de las tres calificaciones analizadas, pero no es ninguna de ellas consideradas independientemente. La definición del modelo de Estado hace referencia a las tres realidades superpuestas: al Estado de derecho en cuanto que la actividad de los poderes públicos debe someterse al ordenamiento jurídico, al Estado democrático, en cuanto que el Estado debe ser expresión del poder del pueblo; al Estado social,

30 Cfr. C. DE CABO, La crisis del Estado social, PPU, Barcelona, 1986.

31 Cfr. P. Lucas Veroú, La lucha por el Estado de Derecho, Studia Albornotiana, Bolonia, 1975, págs. 91-124.

32 Cfr. F. Fernández Segado, El sistema constitucional español, Dykinson, 1992, págs. 109-126.

33 Cfr. A. Garrorena Morales, El Estado Español como Estado social y democrático de Derecho, Tecnos, Madrid, 1984, págs. 199-217.

34 Cfr. A. Troncoso Reigada, Privatización, Empresa Pública y Constitución, Marcial Pons, Madrid, 1997. 
en tanto que el funcionamiento del Estado debe enlazar con la dinámica de la sociedad sobre la que se asienta 35 .

El hecho de que la calificación de nuestro Estado como social y democrático de derecho se encuentre situada en el Título Preliminar hace que ésta forme parte de la fórmula politica de nuestra Constitución, una suerte de súper legalidad constitucional, lo que justifica su especial protección frente a la reforma constitucional - art. $168 \mathrm{CE}-36$. Su reforma no significaría una mera modificación constitucional sino la elaboración de otra Constitución. En Alemania, la fórmula del art. 20.1 o 3 y 28.1 -que define la República como un Estado federal democrático y social y como un Estado social de derechose encuentra protegida por la cláusula de intangibilidad del art. 79.337.

Las nuevas tareas que la Constitución atribuye al Estado contribuyen a transformar a la Administración. Asi, el Estado social complicó la organización administrativa, dando más competencias a las Administraciones territoriales 38 y creando una multiplicidad de Administraciones institucionales 39 . El Estado social y democrático de derecho se caracteriza también por una configuración muy pluralista, que facilita la representación de inte-

35 Señala Aparicio que uno de los rasgos más característicos del constitucionalismo moderno es la constitucionalización de principios contradictorios, como la igualdad real del art. 9 CE y la dignidad de la persona del art. $10 \mathrm{CE}$. Para Aparicio, la igualdad real no entronca con el Estado social sino con el Estado democrático de derecho. Para este autor, no cuadra porque, a pesar de que el principio de igualdad real y efectiva es un desideratum graduable, el Estado social es negado estructuralmente por el modelo social y económico que acompaña a ese mismo Estado social. La desigualdad económica de base únicamente puede transformarse en su contrario si el propio modelo constitucionalizado desaparece. No cabe entre ellos una integración, por muy dialéctica que se pretenda. Cfr. M. A. ApARIcIo, Introducción al sistema político y constitucional español, Ariel, Barcelona, 1993, págs. 95-96.

36 Cfr. R. CANOSA, Interpretación constitucional y fórmula política, CEC, Madrid, 1988, págs. 249-310. No obstante, el concepto constitucional de la fórmula política, aplicados a la interpretación constitucional, es de muy difícil comprensión.

37 Cfr. P. DE VEGA, La reforma constitucional y la problemática del poder constituyente, Tecnos, Madrid, 1985, págs. 247-267.

38 Cfr. A. Porras NAdAlEs, "Estado social y Estado autonómico", en Estudios de Derecho Publico: Homenaje a Juan José Ruiz Rico,Tecnos, Madrid, 1997; G. RuIz-Rıco, "EI Estado social autonómico: eficacia y alcance de las normas programático-sociales de los Estatutos de Autonomía", REDC núm. 65, 2002, págs. 11-48.

39 Cfr. AA. W, La Administración instrumental. Libro homenaje a Manuel Francisco Clavero Arévalo, Civitas-Universidad de Sevilla, 1994. G. ARIÑO, "La iniciativa pública en la Constitución. Delimitación del sector público y control de su expansión", RAP, núm. 88, 1979, págs. 55-106; también en 34 artículos seleccionados de la Revista de Administración Pública con ocasión de su centenario, INAP, Madrid, 1983, págs. 988-1039. 
reses sociales ${ }^{40}$. Se trata así de dar respuesta a los problemas de organización y de representación de una sociedad más heterogénea y conflictiva que la liberal, donde las clases populares van asumiendo un papel activo y determinante junto con la burguesía. Frente al Estado liberal, que no admitía intermediación entre el Estado y el individuo y excluía la representación de intereses colectivos, las Constituciones sociales atribuyen a grupos como sindicatos y organizaciones empresariales -también a partidos politicos-relevancia constitucional. Se supera así una visión individualista de la sociedad, donde la Constitución no es ya un pacto entre el Soberano y la nación sino un acuerdo entre fuerzas sociales y políticas que conviven en el mismo Estado y aceptan unas reglas de juego que deben respetar. Esto permite dar una mayor prioridad a la cuestión social, al permitir la organización de grupos de interés - los desempleados, los mayores, las madres con niños-. Así, sindicatos y organizaciones empresariales tienen capacidad para firmar convenios colectivos con fuerza normativa, haciendo valer su voluntad delante del Estado. Se establece así una relación triangular, donde el Estado interviene como mediador entre las partes sociales, es garante de los acuerdos y representante de los intereses nacionales. El Estado social admite asi un cierto neo-corporativismo 41 .

El Estado social se caracteriza por una primacía del Derecho público sobre el Derecho privado. La Administración sirve al interés general y desarrolla una actividad prestacional de los derechos fundamentales, lo que justifica su preeminencia sobre los particulares y que su actividad tenga un conjunto de privilegios en sus relaciones con los ciudadanos sustanciados en el Derecho administrativo. Se supera así el reconocimiento del valor del Derecho privado, basado en la ficción de la igualdad de las partes y que congelaría las posiciones de desigualdad.

\section{MANIFESTACIONES HISTÓRICAS DEL ESTADO SOCIAL}

Si lo característico del Estado social es el principio de solidaridad, sus primeras manifestaciones se producen a través de obligaciones legales más que de exigencias constitucionales. En la historia del derecho, el Legislador

40 Cfr. M. García Pelayo, Las transformaciones del Estado contemporáneo, Madrid, 1977, págs. 108-136.

41 La representación de intereses desde la teoría constitucional ha sido estudiado entre nosotros por L. GARCía RUIz, El Consejo Económico y Social, CES, Madrid, págs. 23-40. 
ha ido frecuentemente por delante del Constituyente. El Derecho administrativo como ordenamiento acogió los primeros avances del Estado social antes de que éste se reflejara en los textos constitucionales.

La educación y la beneficencia, a partir de la Declaración de Derechos de 1793, representan las dos grandes excepciones a la ideología de abstención del Estado en las tareas de prestación social y son los primeros servicios públicos de carácter general sobre los que existe una responsabilidad de la Administración 42 .

A pesar de que a finales del siglo XIX el ambiente era poco favorable a las intervenciones públicas, el Estado obligó a los empresarios a asegurar a los trabajadores contra los infortunios en el trabajo. Hasta ese momento, los primeros ejemplos de prevención nacían como formas privadas dentro de las mutualidades y casas de socorro donde la solidaridad de los socios no se extendía a los grandes sucesos y eran prestaciones modestas. La intervención del Estado por medio de la actividad legislativa cubría principalmente las condiciones de trabajo en las fábricas: Ley italiana de 17 de marzo de 1898, Ley de Salud y Moralidad para regular el trabajo de niños en las fábricas de algodón - Inglaterra, de 1802-, del horario laboral de doce horas - Francia, en 1892-, descanso semanal obligatorio y seguro de enfermedad para trabajadores Alemania, en 1883-. El desarrollo de una legislación laboral es otra de las primeras manifestaciones del Estado social. El Derecho civil partía de la autonomía contractual, expresión de la libre decisión del individuo, que no tenía en cuenta la desigualdad de medios económicos que situaba al trabajador en una situación de debilidad y dependencia del empresario. Las leyes que van regulando las relaciones laborales protegen a la parte más débil de la relación jurídica atribuyendo a los trabajadores unos derechos irrenunciables. En la misma dirección se ha producido de manera paulatina el desarrollo del derecho de los consumidores como límite a la legislación mercantil y como protección del usuario o consumidor frente a la empresa privada 43 .

Progresivamente va correspondiendo al Estado el establecimiento de un sistema de seguridad social. Este sistema de previsión social se va a caracterizar por la falta de correspondencia entre el riesgo y la contribución, y la irrelevancia de la proporcionalidad entre la contribución y la pres-

42 Cfr. S. MuÑoz MaCHADO, Servicio público y mercado, cit, págs. 54-72.

43 Cfr. L. Lópzz Guerra, "Las dimensiones del Estado social de Derecho", Sistema, núms. 38-39, 1980, págs. 171-191. 
tación. Se establece así un sistema de previsión social solidaria y se supera el modelo mutualístico, que tenía influencia del modelo de aseguramiento privado. El peso del sistema lo asumen los miembros individuales con mayor capacidad contributiva. Las aseguraciones sociales eran obligatorias por Ley, obligación que grava especialmente al empresario. Si el empresario obtiene un beneficio de la actividad del trabajador, también debe soportar el riesgo económico que puede acompañar al normal desempeño de su actividad laboral, en particular, los accidentes de trabajo. Con los años se va acentuando el carácter público de la tutela de la previsión social, a la vez que se extiende a situaciones de invalidez y vejez ${ }^{44}$.

Las crisis económicas -especialmente la de 1929-, que dio lugar a la Gran Depresión, evidenciaron que el libre juego de las fuerzas sociales - la competitividad, la ley de la oferta y de la demanda - no es capaz de garantizar unas condiciones mínimas de vida. Antes y después surgieron Institutos de Previsión Social. El Istituto Nazionale della Previdenza Sociale -INPS - creado originariamente por Ley de 1898, fue organizado según una Ley de 1935, en pleno período de Mussolini. El Gobierno fascista italiano y la dictadura franquista se caracterizaron por aprobar Cartas del trabajo que postulaban o imponían la colaboración - se quería que fuese orgánica-entre empresario y trabajador, como ejemplo de una ideología corporativa. Progresivamente se establecieron en estos paises pensiones de vejez, de invalidez, por obligaciones familiares, por accidentes de trabajo, y se fue creando un sistema sanitario público con pretensiones de globalidad 45 .

El modelo británico de Seguridad Social nace con el Informe Beveridge - Social Insurance and Allied Service-, de 1942, cuyos principios se ponen en marcha por el Gobierno laborista, especialmente de 1946 a 1950. Este proyecto de Seguridad Social aseguraba un mínimo de renta en relación con cualquier circunstancia que pudiera disminuir los ingresos económicos, como el desempleo, la enfermedad, la vejez y la muerte, además de establecer un Servicio Sanitario Nacional - National Health Service- que hacía compatible la nacionalización de los hospitales y la

44 Cfr. M. Alonso Olea y J. L. Tortuero Plaza, Instituciones de Seguridad Social, Cívitas, Madrid, 1998.

45 Cfr. F. Garrido Falla, L. E. De la Villa y R. Marín Mateo, Problemas fundamentales de beneficencia y asistencia social, Ministerio de la Gobernación, Madrid, 1967; E. Baldoni, "I servizi sociali", en G. Amato y A. Barbera, Manuale di diritto pubblico, $4^{\mathrm{a}}$ ed. Bologna, 1994 , págs. $843-856$, esp. págs. 844-847. Más ampliamente M. PersiANI, Lezioni di diritto della previdenza sociale, Cedam, Padova, 1981. 
gratuidad de algunas prestaciones, con iniciativas de previsión y asistencia privada46. El Modelo escandinavo, que nace a partir de los años 30 , tuvo un gran desarrollo en los Estados nórdicos -Dinamarca, Suecia, Noruega - y se caracterizaba por un aumento progresivo de la gama de prestaciones sociales bajo un sistema fiscal progresivo muy desarrollado. Poco a poco todos los países occidentales se han ido dotando de un sistema público de seguridad social47. También los países del este europeo durante el período de dominación comunista tenían un modelo de Estado asistencial, a través de una planificación centralizada, pero la diversidad de presupuestos ideológicos y la ausencia de una economía de mercado hacen difícil confrontar sus experiencias con el mundo occidental48.

En general, la actividad del Estado social se ha dirigido principalmente a la seguridad social, sanidad y educación, desarrollando en estos ámbitos prestaciones directas ${ }^{49}$. A lo largo de los siglos $\mathrm{XIX}$ y $\mathrm{XX}$ se va pasando de sistemas de seguros sociales mixtos - con fondos de trabajadores, empresarios y Estado- a sistemas financiación estatal y de cobertura nacional. Se amplían prestaciones de la Seguridad Social, extendiéndose a la cobertura del desempleo y a las pensiones no contributivas. En el ámbito educativo y sanitario, de manera progresiva se ha tratado de universalizar estos servicios, extendiendo la gratuidad cada vez a más niveles y tratando de mantener unos estándares de calidad adecuados 50 . La labor del Estado social se extiende a otros aspectos de la vida como a la vivien-

46 Cfr. A. Troncoso ReIgada, "Notas sobre el servicio público", RVAP núm. 59, 2001, pág. 378.

47 La evolución en EEUU es, como es sabido, distinta. Una demostración del menor grado de desarrollo del Estado social en EEUU es la limitada actividad de las llamadas social welfare agencies y de las social regulatory agencies. Cfr. B. ScHWARTZ, Administrative Law, Little Brown and Company, 1991, págs. 2-6, 16-19 33-35 y 180-182.

48 Sobre el Estado como distribuidor y algunas de sus consecuencias estructurales, cfr. M. García Pelayo, Las transformaciones del Estado contemporáneo, cit. págs. 31-40.

49 Cfr. J. PemÁn GaVín, "Del seguro obligatorio de enfermedad al sistema nacional de salud", RAAP núm. 13, 1998, págs. 61-97. Un estudio sobre la sanidad pública en España durante el siglo XIX se puede ver en R. NAVARro, Historia de la Sanidad en España, Lundwerg 2002, págs. 94-132.

50 Cfr. J. M. Fernández PAStRana, El servicio público de la sanidad: el marco constitucional, Civitas, Madrid, 1984; S. MuÑOz MACHADO, La formación y la crisis de los servicios sanitarios públicos, Alianza, Madrid, 1995; S. MUÑOZ MACHADO, "La organización, las prestaciones y otros problemas jurídicos actuales de los servicios sanitarios", RVAP núm. 57, 2000, págs. 49-65; 
da, al ocio y al deporte. En general, el esfuerzo de redistribución de los recursos y de la aproximación de las rentas se quiere desarrollar a través de servicios y prestaciones del Estado asistencial ${ }^{51 .}$

Junto con la labor de previsión social, comienzan a formarse a finales del XIX y principios del $\mathrm{XX}$ los primeros grandes servicios públicos económicos como el servicio de correos, el de teléfonos, el de suministro eléctrico y el de televisión. Es de destacar cómo estos servicios públicos fueron desarrollados inicialmente tanto por el Estado en régimen de monopolio como por particulares a través de concesión administrativa52. La categoría del servicio público tiene su origen a finales del siglo $\mathrm{XIX}$ en Francia con la paternidad doctrinal de Haoriou y Duguit, $y$, especialmente, de su Consejo de Estado - arrêt Blanco de 8 de febrero de 1873 y arrêt Terrier de 6 de febrero de $1903-53$.

En general, el Estado Social ha tenido durante el siglo $X X$ muchas manifestaciones de orden económico y financiero. Así, los poderes públicos han orientado la actividad económica, impulsando el desarrollo económico en zonas deprimidas y desarrollando políticas activas de empleo. La expansión de la industria y del comercio ha requerido que el Estado lleve a cabo una política de infraestructuras. Esto ha sido posible gracias a un crecimiento progresivo del producto interior bruto, que permitió el incremento de los impuestos y de las cotizaciones sociales. El Estado comienza a controlar, de esta manera, entre el $30 \%$ y el $50 \%$ de la renta nacional54.

51 Cfr. E. Forsthoff, Stato di diritto in transformazione, Giuffré, Milano, 1973, N. LuHManN, Stato di diritto e sistema sociale, Napoli, 1978.

52 Cfr. A. Troncoso ReIGADA, “Notas sobre el servicio público”, cit. págs. 375-380.

53 Cfr. S. Muñoz MACHAdo, Servicio público y mercado, cit, págs. 99-138. Cfr. A. Troncoso ReIGADA, "Dogmática administrativa y Derecho Constitucional: el caso del servicio público", REDC núm. 57, 1999, págs. 87-164.

54 Cfr. G. Amato, "Forme di Stato e forme di gobernó", G. Amato y A. Barbera, Manuale di diritto pubblico, cit, págs. 61-62. Lógicamente, esto tiene también sus riesgos para el equilibrio económico del propio Estado. Cfr. J. O'CoNNOR, La crisis fiscal del Estado, Barcelona, 1981; M. ARAGón, Los problemas del Estado social, Sistema, núms. 118-119, 1994, págs. 23-32; G. ARiÑo, Economía y Estado. Crisis y reforma del sector público, Marcial Pons, Madrid, 1993; G. Ariño, J. M. De La Cúttara y J. L. Martínez LópezMuÑiz, El nuevo servicio público, Marcial Pons, Madrid, 1997, págs. 17-56. 


\section{LOS DERECHOS SOCIALES EN LA CONSTITUCIÓN ESPAÑOLA DE 1978.}

Una de los elementos caracterizadores del Estado social es la afirmación de que toda persona, en razón de su dignidad, debe disponer de unos recursos materiales mínimos, para lo que puede solicitar asistencia estatal. La cláusula del Estado social está íntimamente vinculada a la garantía de la dignidad de la persona. La Ley Fundamental de Bonn señala la dignidad del hombre como supremo valor. Ahora bien, nuestra Constitución en el art. 10.2 recuerda que la dignidad de la persona y los derechos inviolables que le son inherentes no se encuentran aislados sino que tienen que ser compatibles con los derechos de los demás.

La afirmación de la dignidad de la persona implica el reconocimiento de unos derechos. El constitucionalismo social aporta a la dogmática de los derechos dos consecuencias: por una parte, el concepto de derecho fundamental, que representa una superación de la visión de los derechos como meramente subjetivos; por otra, que a los derechos tradicionales del Estado liberal - los derechos de la esfera personal - y del Estado democrático los derechos políticos - tienen que añadirse unos derechos sociales, inherentes al bienestar de los ciudadanos, que impliquen prestaciones asistenciales -educación y salud- y que abarquen sus relaciones laborales y económicas. Por último, hay que señalar que el Estado social se caracteriza por la constitucionalización de unos principios rectores de la política social y económica que informan la actividad de los poderes públicos.

a) La vertiente prestacional de los derechos de libertad.

El Estado social se ha caracterizado no sólo por la inclusión de nuevos derechos económicos y sociales sino por el reconocimiento de que todo derecho de la esfera personal y de libertad tiene también una vertiente prestacional, que es responsabilidad de los poderes públicos. Como ya hemos señalado en otra ocasión, la noción de derecho fundamental implica que todo derecho, a partir de su reconocimiento constitucional, no sólo tiene una vertiente subjetiva - un substrato subjetivo que exige una la abstención de los poderes públicos en unas esferas de libertad individuales- sino también una vertiente objetiva, que implica la obligación de los poderes públicos de desarrollar una actividad prestacional en garantía de la efectividad del mismo. Todo derecho fundamental es, a la vez, un derecho de libertad y un derecho de prestación 55 .

55 Cfr. E-W. BÖKENFÖRDE, Escritos sobre Derechos Fundamentales, Nomos, 
Así, el secreto de las comunicaciones - art. 18.3 CE- y la propia libertad de expresión requiere que el Estado garantice la existencia de una red de comunicaciones postales, telegráficas y telefónicas universales y a un precio adecuado; la libertad personal y las garantías de la detención art. $17 \mathrm{CE}-$ exige un procedimiento de habeas corpus, la asistencia de letrado y la necesidad de intérprete; el derecho a la tutela judicial efectiva implica el derecho a una asistencia letrada si se carecen de medios económicos para litigar - art. $24 \mathrm{CE}-$; la libertad de cátedra - art. 20.1.c- exige la existencia de Universidades públicas, etc ${ }^{56}$.

De esta forma, los derechos fundamentales se transforman en principios objetivos del orden constitucional ${ }^{57}$. Los derechos fundamentales, como derechos de prestación o de participación en prestaciones estatales, materializan la orientación del Estado moderno hacia el aseguramiento social. No obstante, como ha señalado el Tribunal Constitucional Federal Alemán, la definición de las concretas prestaciones materiales abarcables en un derecho fundamental es una tarea del legislador, no del poder judicial. La ausencia de suficiente concreción sobre las prestaciones a las que se tiene derecho no es sustituible a través de singulares fallos judiciales. De esta forma, la vertiente subjetiva del derecho fundamental - su parte de derecho de libertad - es más directamente accionable ante los poderes públicos y exigible ante los tribunales; en cambio, la vertiente objetiva o prestacional tiene una estructura distinta que requiere en muchas ocasiones una concreción legislativa y una acción administrativa que la haga efectiva.

Baden-Baden, 1993, págs. 44-72; L. AGUIAR DE LuQUE, "Dogmática y teoría jurídica de los derechos fundamentales en la interpretación de éstos por el Tribunal Constitucional Español", RDP, núm. 18-19, 1983, págs. 17-30; L. Martín-Retortillo Baquer y I. De OtTo y PARDo, Derechos fundamentales y Constitución, Cívitas, Madrid, 1988, págs. 79-83 y 151171; A. E. Pérez LuÑo, Los derechos fundamentales, $3^{2}$ ed. Técnos, Madrid, 1988, págs. 1921 y Derechos Humanos, Estado de Derecho y Constitución, $4^{\mathrm{a}}$ ed. Tecnos, Madrid, 1991, págs. 212-249; H. P. SCHNEIDER, "Peculiaridad y función de los derechos fundamentales en el Estado constitucional democrático", en id., Democracia y Constitución, CEC, Madrid, 1991, págs. 119-149.

56 Cfr. A. Troncoso Reigada, “Dogmática administrativa y Derecho Constitucional: el caso del servicio público", cit. págs. 151-155.

57 K. HeSSE, "Significado de los derechos fundamentales", en BENDA, MAiHOFER, Vogel, Hesse, Hiede, Manual de Derecho Constitucional, cit. págs. 91-94; K, Hesse, Grundzüge des Verfassungsrechts der Bundesrepublik Deutschland, 18 ${ }^{\circ}$, ed, C. F. Müller, Heidelberg, 1991, págs. 153-176. 
Así, la libertad de expresión y de información a través de televisiones privadas - art. 20 - estuvo supeditado a la existencia de una regulación; el derecho de utilizar las lenguas autóctonas ante la Administración General del Estado o en los Tribunales -art. 3.2 CE- ha dependido de la normativa y de la capacidad administrativa de los poderes públicos; la libertad religiosa - art. $16 \mathrm{CE}$ - puede implicar la posibilidad de habilitar espacios para el culto público en determinados lugares que está supeditado a las posibilidades económicas y de espacio - capillas y ministros de culto en cárceles, hospitales públicos, cuarteles-; el derecho a la reeducación, a la reinserción social, al trabajo o al acceso a la cultura de la persona privada de libertad - art. $25 \mathrm{CE}$ - depende de la capacidad económica y de medios del Estado; el derecho de participación política - art. 23 CE - y el ejercicio de la libertad sindical - art. $28 \mathrm{CE}$ - exige unos medios financieros y materiales que aportan los poderes públicos según la normativa y su capacidad; el derecho de participación política conlleva el derecho de acceso a medios informativos públicos autonómicos para la campaña electoral en el caso de que existan; el derecho de acceso a la función pública del art. $23 \mathrm{CE}$ depende de la provisión de plazas por parte de la Administración pública; la libertad de creación de centros docentes y la obligación de los poderes públicos de ayudarlos - art. 27.6 y $9 \mathrm{CE}$ - puede implicar la posibilidad de firmar conciertos económicos según las posibilidades presupuestarias, etc.

\section{b) Los derechos sociales como derechos fundamentales.}

Una característica específica del constitucionalismo social es la inclusión en las declaraciones de derechos, como derechos fundamentales, de algunos derechos considerados sociales, destinados a garantizar el ámbito existencial y laboral de los individuos y de los grupos sociales 58 . Las distintas generaciones del constitucionalismo han materializado transformaciones en la parte dogmática, para incluir como derechos fundamentales, y por tanto, al mismo nivel que los tradicionales derechos de la esfera personal y derechos políticos - libertad ideológica y religiosa, libertad personal, derecho de participación política, etc. - nuevos derechos, al hilo de las preocupaciones sociales y también de la capacidad económica del Estado ${ }^{59}$. Los derechos fundamentales de carácter social se distinguen de

58 Un análisis de los derechos fundamentales sociales en la estructura de la Constitución se puede ver en E-W. BöCKENFÓRDE, Escritos sobre Derechos Fundamentales, cit, págs. 72-81.

59 Cfr. E. BALdonı, "I servizi sociali", cit. pág. 843. 
los derechos de la esfera personal en que ya no son libertades frente al Estado, sino puros derechos de prestación 60 .

Entre estos derechos sociales, que tienen el carácter de derechos fundamentales, encuadraríamos el derecho a la educación - art. $27 \mathrm{CE}-$ que incluye una enseñanza básica obligatoria y gratuita; la libertad sindical art. 28.1 CE-; el derecho de huelga - art. 28.2-; el derecho al trabajo -a una remuneración suficiente para satisfacción de las necesidades regulada por la normativa del salario mínimo - y a no ser despedido por causa de discriminación - art. $35 \mathrm{CE}-$; el derecho a la negociación colectiva entre los representantes de los trabajadores y la fuerza vinculante de los convenios - art. $37.1 \mathrm{CE}-$; el derecho de los trabajadores y de los empresarios a adoptar medidas de conflicto colectivo - art. 37.2 CE-. La Constitución atribuye a estos derechos un conjunto de garantías genéricas y abstractas - aplicación inmediata sin desarrollo legal, reconocimiento de su contenido esencial, reserva de ley, recurso de inconstitucionalidad-, a las que se unen unas garantías específicas - amparo judicial o ordinario, amparo constitucional - para aquellos que se encuentren recogidos en la Sección $1^{\text {a }}$ del Capítulo II del Título 161.

Mención específica merece el derecho a recibir una asistencia sanitaria, que se derivaría del derecho a la vida - art. $15 \mathrm{CE}-$. Este derecho tiene una vertiente prestacional, objetiva, que hace referencia a labor activa de los poderes públicos en garantía del mantenimiento de la vida y de la integridad física a través de una atención sanitaria, bien directamente - gestión directa o gestión indirecta a través de entes o empresas públicas-, bien a través de empresas privadas con servicios financiados por el Estado. Este derecho es distinto del de protección de la salud, reconocido dentro de los principios rectores de la política social y económica que después veremos - art. $43 \mathrm{CE}-$ y que reflejaría las políticas de salud pública. En esta misma dirección, dentro del derecho al trabajo - art. $35 \mathrm{CE}$ - estaría el derecho a las prestaciones de la seguridad social en caso de necesidad y desempleo - art. $41 \mathrm{CE}-$. De hecho, unas de las prestaciones típicas del régimen de la seguridad social es la asistencia sanitaria.

60 Los derechos a prestaciones en sentido estricto, considerados como derechos a acciones positivas del Estado y como derechos sociales fundamentales, han sido analizados por R. AlEXY, Teoría de los derechos fundamentales, CEC, Madrid, 1997, págs. 419-435 y 482-502.

61 Cfr. J. L. CASCANO, La tutela constitucional de los derechos sociales, Madrid, 1988. Cfr. más ampliamente M. CARRILLO, La tutela de los derechos fundamentales por los tribunales ordinarios, CEC, Madrid, 1995, págs. 132-142; J. GARCía MoRILLO, La protección judicial de los derechos fundamentales, Tirant lo blanch, Madrid, 1994, págs. 65-67. 
Así, en esta dirección la Carta de los Derechos Fundamentales de la Unión Europea, que recoge en un único texto, por primera vez en la historia de la Unión Europea, el conjunto de los derechos civiles, hace referencia al ámbito sanitario y a las prestaciones de la seguridad social62. Así, el artículo 35 de la Carta Europea reconoce el derecho a la protección de la salud, a la prevención sanitaria y a beneficiarse de la atención sanitaria en las condiciones establecidas por las legislaciones y prácticas nacionales. Igualmente, el artículo 34 de la Carta Europea reconoce y respeta el derecho de acceso a las prestaciones de seguridad social y a los servicios sociales que garantizan una protección en casos como la maternidad, la enfermedad, los accidentes laborales, la dependencia o la vejez, así como en caso de pérdida de empleo. No olvidemos que tempranamente la Carta Social Europea, de 18 de octubre de 1961, afirmaba que toda persona que carezca de recursos suficientes tiene derecho a la asistencia social y médica y a beneficiarse de los servicios de bienestar social.

c) Los principios rectores de la política social y económica.

La actividad social del Estado que describen las Constituciones no se reduce a los derechos. Así, nuestra Constitución recoge en el Capítulo III del Titulo I unos principios rectores de la política social y económica, materialización efectiva de la opción por un Estado social, que deben orientar la legislación positiva, la práctica judicial y la actuación de los poderes públicos, pero que sólo pueden ser alegados de acuerdo con lo que dispongan las leyes que los desarrollen63. Por tanto, las prestaciones que alli se contienen no son derechos fundamentales - no tiene aplicación inmediata ni una vertiente objetiva ex constitutione exigible a los poderes públicos-, ni tienen contenido esencial - en el enjuiciamiento de la legitimidad del desarrollo legislativo no se puede ir de lo abstracto a lo concreto-. Se está a expensas del desarrollo legislativo, en donde el legislador tiene un amplio margen de libertad, para que nazcan pretensiones jurídicas concretas invocables ante los Tribunales. Es decir, los principios rectores no atribuyen derechos subjetivos individuales sino que son normas definidoras de tare-

62 Cfr. S. Muñoz Machado, J. L. Garcia Delgado y L. González Seara, Las estructuras del bienestar en Europa, Civitas-Escuela Libre, Madrid, 1999.

63 Una visión más amplia de lo que representan los principios rectores de la política social y económica para el cumplimiento de las metas político-sociales de la Constitución se puede ver en P. LUCAS Verdú, Estimativa y política constitucionales, Facultad de Derecho, Universidad Complutense, 1984, esp. págs. 147-209. 
as del Estado que están a la espera de una configuración administrativa concreta. En todo caso, pueden ser de extraordinaria importancia para interpretar los derechos fundamentales 64 .

Así, dentro de los principios rectores de nuestra Constitución -arts. 39-52 CE-, destacaríamos tres grandes grupos: los principios de política económica, laboral y social; los principios orientados a la protección de determinados colectivos, especialmente de los trabajadores; y los principios que pretenden potenciar derechos de tercera generación. Lógicamente, esta clasificación es forzada ya que los principios de política económica y laboral protegen a un colectivo como el de los trabajadores o reconocen derechos a recibir prestaciones de seguridad social; la protección de determinados colectivos atribuye a éstos derechos que pueden ser considerados de tercera generación como los derechos de los discapacitados o de los jóvenes; por último, la materialización de los derechos de la tercera generación, como el de la vivienda, exige una determinada política económica, urbanística y de utilización del suelo.

Dentro de los principios de política económica, laboral y social estarían los siguientes: obligación de los poderes públicos de promover las condiciones para el progreso social y económico y para la distribución equitativa de la renta, así como de desarrollar una política orientada hacia el pleno empleo, sin perjuicio del mantenimiento de la estabilidad económica - art. $40.1 \mathrm{CE}-$; fomento de una política de formación y readaptación profesionales, velando por la seguridad e higiene en el trabajo y garantizando el descanso necesario, mediante la limitación de la jornada laboral y las vacaciones periódicas retribuidas - art. 40-; mantenimiento de un régimen público de Seguridad Social que garantice la asistencia y prestaciones sociales suficientes ante situaciones de necesidad, especialmente en caso de desempleo - art. 41-; garantía de unas pensiones adecuadas y de su suficiencia económica - art. 50-; defensa de los consumidores y usuarios - art. 51-; y garantía del funcionamiento de las organizaciones profesionales que tutelan los intereses sociales que le sean propios - art. $52 \mathrm{CE}-$.

Dentro de los principios orientados a la protección de determinados colectivos estarían los siguientes: protección social, económica y jurídica

64 Cfr. J. Pérez RoYo, "La doctrina del Tribunal Constitucional sobre el Estado Social", REDC, núm. 10, 1984, págs. 157-181. La doctrina del Tribunal Constitucional sobre el Estado social se encuentra expuesta en las Sentencias 18/1984, de 7 de febrero; 11/1981, de 8 de abril; 6/1981, de 6 de abril; 42/1982, de 5 de julio; 3/1983, de 25 de enero; 19/1982, de 5 de mayo y 146/1986, de 25 de noviembre. 
de la familia, los niños, las madres solteras y los hijos extramatrimoniales art. 39 CE-; protección de los emigrantes y de sus derechos económicos y sociales - art. $42 \mathrm{CE}$-; protección de la juventud y de su participación en el desarrollo político, social, económico y cultural -art. $48 \mathrm{CE}-$; protección de los disminuidos físicos, sensoriales y psíquicos, a través de su tratamiento, rehabilitación e integración - art. 49-; promoción del bienestar de la tercera edad y de su acceso a un sistema de servicios sociales que atiendan a sus problemas de salud, vivienda, cultura y ocio - art. 50-; protección de los consumidores y usuarios, en especial en lo que hace referencia a su seguridad, salud e información -art. 51-;

Por último, dentro de los principios que pretenden potenciar derechos de tercera generación estarian los siguientes: derecho a la protección de la salud, a través de medidas preventivas, de las prestaciones y servicios necesarios y del fomento de la educación física, el deporte y la adecuada utilización del ocio - art. 43-; derecho al acceso a la cultura, la ciencia y la investigación - art. 44-; derecho a un disfrute de un medio ambiente adecuado para el desarrollo de la persona y a la utilización racional de los recursos naturales - art. $45 \mathrm{CE}-$; derecho a la conservación y el enriquecimiento del patrimonio histórico, cultural y artístico -art. 46-; derecho al disfrute de una vivienda adecuada - art. 47-65. Algunos de estos derechos, como el derecho al medio ambiente o al patrimonio, son derechos colectivos, relativos a bienes que son sobreentendidos y considerados base de la misma vida y de la tradición del hombre, pero que comienzan a ser escasos y cuya desaparición amenazaría a toda la colectividad en su conjunto66.

A veces la opinión pública desarrolla una comprensión inocente y escasa de formación jurídica de estos principios rectores de la política social y económica, y llega a confundirlos con derechos efectivos, que no encuentran cumplimiento. Parece como si el Estado prometiera algo que no puede satisfacer con lo que resultarían frustradas las expectativas despertadas. Es necesario, por ello, resaltar su carácter de principios que no pueden fundamentar pretensiones individuales sino que imponen tareas al Estado, $y$ a los que se debe orientar la acción de los poderes públicos. Afortunadamente, muchos de estos principios se han convertido $y$ desarrollado a través de legislaciones específicas en derechos efectivos, como los límites de jornada

65 Un análisis sobre los derechos a la calidad de vida y al medio ambiente, y a la tutela del patrimonio histórico-artístico se puede ver en A. E. PÉrEZ LuÑo, Derechos Humanos, Estado de Derecho y Constitución, cit. págs. 440-491.

66 L. López GuerRA, Introducción al Derecho Constitucional, cit. pág. 105. 
laboral y las vacaciones retribuidas de los trabajadores, el derecho de las personas con discapacidad al acceso al empleo mediante el establecimiento de cupos, la garantía del crecimiento de las pensiones al menos al ritmo de la inflación o el derecho al acceso a centros de día y de residencias permanentes de las personas mayores 67 . A la hora de determinar si estos derechos mencionados en los principios rectores de la política social y económica son sólo para españoles o también para extranjeros, hay que analizar la legislación específica que los desarrolle.

Un principio rector del Estado social que a menudo se olvida es el regulado en el art. 9.2 $\mathrm{CE}$, que establece como una obligación de los poderes públicos upromover las condiciones para que la libertad y la igualdad del individuo $y$ de los grupos en que se integra sean reales y efectivas, remover los obstáculos que impidan o dificulten su plenitud y facilitar la participación de todos los ciudadanos en la vida política, económica, cultural y social». No basta que los poderes públicos garanticen únicamente la igualdad formal, es decir, la igualdad ante la Ley - que la Ley fuera para todos y que se aplicara igualmente a todos-. Si los poderes públicos pretendieran únicamente una igualdad formal, congelarían situaciones de desigualdad y beneficiarían a los más privilegiados. Es necesario que los poderes públicos orienten su actividad hacia la consecución de la igualdad material. Esta es una labor que le corresponde al legislador, lo que sensu contrario significa que no le corresponde al Juez. Así, en la búsqueda de la igualdad efectiva, el legislador distingue situaciones dentro de la Ley, para alcanzar la igualdad promocional, así como para respetar el propio contenido del principio de igualdad que exige tanto un trato igual a situaciones iguales como un trato distinto a situaciones distintas. Igualmente, el legislador se sirve de la discriminación positiva o affirmative action, que significa clasificar utilizando categorias determinadas que han sido tradicionalmente causas de discriminación, empleándolas ahora para otorgar ventajas a estos colectivas. La cobertura de este trato desigual se justifica en la situación fáctica de inferioridad y en la obligación que tienen los poderes públicos de promover la igualdad y de remover los obstáculos que dificulten su plenitud -art. 9.2-.

67 Cfr. J. L. Beltrán AguirRe, El régimen juridico de la acción social pública, IVAP, Oñati, 1992; idem, “Los servicios sociales", RVAP núm. 57, 2000, págs. 113-139; G. CÁmARA y J. CANO, Estudios sobre el Estado social, Madrid, 1993. Un intento de clasificación dogmática de la actuación social de la Administración pública se puede ver en M. VAOUER Caballería, "Los servicios atinentes a la persona en el Estado social", Cuadernos de Derecho Público, núm. 11, 2000, págs. 31-72. 


\section{LOS DERECHOS SOCIALES EN LA GUARDIA CIVIL.}

\section{LA GUARDIA CIVIL COMO INSTITUCIÓN. SU CARÁCTER CIVIL Y MILITAR. LAS FUNCIONES DE LA GUARDIA CIVIL.}

La Guardia Civil es un instituto armado de naturaleza militar perteneciente a las Fuerzas y Cuerpos de Seguridad del Estado, que fue fundado por el Duque de Ahumada, hombre de confianza del general Narváez, a través de los Decretos de 28 de marzo y 13 de mayo de 1844, en el comienzo del Reinado de Isabel II. Fue impulsado por el Gobierno moderado de González Bravo con el consenso de las fuerzas políticas, que vieron la necesidad que tenía el Estado liberal español de disponer de una fuerza de seguridad pública para abarcar todo el territorio peninsular y para hacer frente a la alarmante situación de inseguridad generada por el bandolerismo que desde la Guerra de la Independencia azotaba los caminos y campos del país. El Duque de Ahumada tomó como ejemplo el modelo implantado en Francia con la Gendarmería y el existente en Cataluña con los Mossos de Escuadra68.

Desde su comienzo la Guardia Civil se configuró como un cuerpo de seguridad pública de naturaleza militar, que dependía del Ministerio de la Gobernación para todo lo referente al servicio y del Ministerio de la Guerra en cuanto a su organización, disciplina, personal, material y percibo de haberes, aunque estaba dotado de una gran autonomía organizativa. La reforma de su estructura de 1 de julio de 1871 reforzó su naturaleza castrense. Durante la I República se intento cambiar la dependencia dual por una exclusiva del Ministerio de la Gobernación, pero no sólo no prosperó sino que con la llegada de la Restauración se produjo un reforzamiento de la Administración militar que llevó a la Guardia Civil a integrarse por primera vez en el Ejército, a través de las Leyes de 29 de noviembre de 1878 y de 19 de julio de 1889. Durante la II República, la Guardia Civil fue segregada del Ministerio de la Guerra, quedando integrada en el Ministerio de la Gobernación, sin cambiar su carácter militar ni su sujeción al fuero castrense. Al comienzo de la guerra civil el Cuerpo fue convertido en la Guardia Nacional Republicana por Decreto de 30 de agosto de 1936. Al término de la guerra la Guardia Civil absorbió al personal y a las funciones del Cuerpo de Carabineros, por Ley de 15 de marzo de $1940^{69}$.

68 Cfr. M. López Corral, La Guardia Civil de hace un siglo, AHGC, Madrid, 1998, págs. 15-62.

69 Hay que destacar el estudio de Miguel López Corral sobre la doble dependencia de la Guardia Civil de los Ministerios de Interior y Defensa. El autor analiza desde 1931 hasta nuestros días los distintos textos legislativos y los hechos de relevancia histórica. Cfr. M. LÓPEZ CoRral, "La disputa competencial en torno a la Guardia Civil", Cuadernos de la Guardia Civil, núm. 22, 2000, págs. 205-222. 
La Constitución Española no hizo mención alguna a la Guardia Civil. La Ley 6/1980, de 1 de julio, por la que se regulan los criterios básicos de la defensa nacional y la organización militar excluyó a la Guardia Civil de las Fueras Armadas. En cambio, la Ley Orgánica 2/1986, de 13 de marzo, de Fuerzas y Cuerpos de Seguridad la incluyó entre las Fuerzas y Cuerpos de Seguridad del Estado, estableciendo que le sería de aplicación, además de determinadas normas específicas, el ordenamiento militar -art. 9-. La Ley 42/1999, de 25 de noviembre, que aprueba el Estatuto de Personal de la Guardia Civil, establecía en su art. 2.1 que dada la condición militar del Instituto en el que se integran sus miembros éstos tienen la consideración de militares de carrera de la Guardia civil.

Por ello, la Guardia Civil tiene una doble dependencia ministerial: del Ministerio del Interior en cuanto a los servicios que se desprenden de la ejecución de la política del Gobierno en materia de seguridad ciudadana, retribuciones, destinos y medios; del Ministerio de Defensa en cuanto a los ascensos del personal y las conocidas como misiones de carácter militar que actualmente se están definiendo en términos de colaboración 70 . La Guardia Civil también atiende las necesidades del Ministerio de Hacienda relativas al resguardo Fiscal del Estado, asi como distintas funciones de defensa de la naturaleza, en estrecha relación con el Ministerio de Medio Ambiente. Igualmente desarrolla otras funciones de control e inspección relacionadas con las competencias de las Administraciones autonómicas y locales ${ }^{71}$.

La Guardia Civil ha sido durante el último siglo y medio un instrumento esencial para garantizar la seguridad y la tranquilidad de los españoles. Como ha señalado COSIDÓ, la Guardia Civil ha sido en nuestra historia contemporánea uno de los elementos conformadores del nuevo Estado Liberal y hoy constituye uno de los pilares del Estado democrático y de derecho, que se instauró en nuestro país con la Constitución de 1978. La Guardia Civil, extendida en todos los rincones de nuestra geografia, es una garantía para los derechos y libertades de todos los ciudadanos y para el cumplimiento de la Ley, además de manifestar la presencia del Estado en toda España72.

70 Cfr. el Manual Institucional de la Guardia Civil, pro manuscrito.

71 Cfr. 8. SALCEDo, "La colaboración de la Guardia Civil con las Comunidades Autónomas", Cuadernos de la Guardia Civil, núm. 22, 2000, págs. 127-138.

72 Cfr. I. Cosıdó, "Introducción" a a I. Cosıdó (coord.), La Guardia Civil más allá del año 2000, FAES, Madrid, pág. 15. 
La Guardia Civil desempeña un conjunto de funciones, entre las que destaca la función de seguridad pública, que permite mantener el orden y la seguridad ciudadana, la vigilancia, control y protección de los espacios públicos e instalaciones, la prevención de la comisión de actos delictivos y la seguridad vial73. Igualmente, la Guardia Civil desarrolla labores de policía judicial, auxiliando a Jueces y Tribunales y colaborando con el Ministerio Fiscal a través de la investigación de delitos, la detención de presuntos delincuentes y la elaboración de peritaciones técnico-policiales. Tiene también una función de policía administrativa, que vela por el cumplimiento de las leyes, garantizando el funcionamiento de los servicios públicos esenciales a las órdenes de las autoridades administrativas, una función de resguardo fiscal del Estado, con la finalidad de evitar y perseguir el contrabando y el fraude 74 , función que está relacionada con la de policía de fronteras, desarrollando también cometidos de seguridad aeroportuaria, control de fronteras exteriores, lucha contra las redes de inmigración irregular y control de dichos flujos. Por último, desarrolla una función de asistencia, como son la protección y auxilio a las personas, el aseguramiento y la custodia de sus bienes y la intervención en los casos de grave riesgo, catástrofe y calamidad pública 75 .

\section{Los derechos sociales de los miembros de la Guardia Civil.}

Para cumplir las funciones y competencias antes descritas, la Guardia Civil cuenta con setenta y tres mil agentes, de los que más de dos mil quinientos son mujeres. Estos miembros de la Guardia Civil son titulares de un conjunto de derechos sociales, como empleados públicos y como ciudadanos. Es indispensable estudiar y avanzar en estos derechos, no solo porque es una exigencia de la Constitución que reconoce derechos sociales para todas las personas en general y para los funcionarios públicos en particular, sino también porque cuidar a las personas - al elemento humano- es un factor que condiciona y es responsable de los éxitos y de los fracasos de la gestión de la Guardia Civil como institución.

73 Cfr. al respecto la Ley Orgánica 2/1986, de 13 de marzo, de Fuerzas y Cuerpos de Seguridad del Estado.

74 Cfr. S. MACARRÓN, “La Guardia civil en la investigación de los delitos contra la Hacienda Pública", Cuadernos de la Guardia Civil, núm. 19, 1998, págs. 137-148.

75 Cfr. B. SALCEDo, "El entono de actuación de la Guardia Civil", I. Cosıdó (coord.), La Guardia Civil más allá del año 2000, cit. págs. 23-137; B. SALCEDo, "Reflexiones en torno a la naturaleza y las misiones de la Guardia Civil", Cuadernos de la Guardia Civil, núm. 19, 1998, págs. 29-48. 
La vigencia de los derechos sociales en la Guardia Civil está condicionado por el origen de esta institución y por su desarrollo en el tiempo. Tradicionalmente, el Cuerpo de la Guardia Civil, si bien desempeñaba funciones policiales, formaba parte del Ejército de Tierra. Por ello, y a excepción de algunas materias específicas, su régimen de personal coincidía con el del Ejército. Vamos a analizar seguidamente algunos de los derechos sociales que, a nuestro modo de ver, merecen un particular estudio.

\section{a) El derecho a una remuneración suficiente.}

Uno de los derechos económicos y sociales más característicos es el derecho a una retribución. Así, hemos señalado anteriormente que el derecho al trabajo - a una remuneración suficiente para satisfacción de las necesidades - es un derecho social que tiene el carácter de derecho fundamental -art. $35 \mathrm{CE}$-. El principal problema de la Guardia Civil en este ámbito reside en la congelación del Capítulo I de su programa presupuestario dentro de los Presupuestos Generales del Estado, que durante muchos años no ha crecido al mismo ritmo que el índice de precios al consumo, debido a las restricciones de los recursos económicos públicos. Además, cualquier subida suponía un carga para el erario público ya que los sueldos actúan como base reguladora para el cálculo de los derechos pasivos 76 .

Ha surgido así una situación de agravio comparativo en términos retributivos, no sólo entre las policías locales y las policías autonómicas, mejor pagadas que las Fuerzas y Cuerpos de Seguridad del Estado, sino entre el Cuerpo Nacional de Policía y la Guardia Civil. La realidad es que el Cuerpo Nacional de Policía dispone de mejores retribuciones que la Guardia Civil77. Esto es debido, en parte, a que los miembros del Cuerpo Nacional de Policía pueden ejercitar la libertad sindical y disponen así de un buen instrumento de negociación, lo que no le ocurre a la Guardia Civil. De hecho, el Tribunal Constitucional ya ha señalado que la fijación del contenido salarial corresponde en general a la autonomía de los trabajadores

76 Cfr. J. A. Santamaría Pastor, Principios de Derecho administrativo, $3^{\circ} \mathrm{ed,} \mathrm{I,}$ Ceura, Madrid, pág. 705. Más ampliamente J. L. PIÑAR MAÑAS, "El nuevo sistema retributivo de los funcionarios y su aplicación", RAP núm. 111, 1986, págs. 345 y ss.

77 Esta diferencia retributiva entre ambos cuerpos está siendo corregida en los Presupuestos Generales del Estado para el 2002, 2003 y 2004. Cfr. sobre la cuestión anteriormente F. Alvaredo, "El Presupuesto de la Guardia Civil: sus líneas generales", Cuadernos de la Guardia Civil, núm. 23, 2000, págs. 59-74. 
y empresarios mediante el ejercicio del derecho a la negociación colectiva que proclama el art. $37.1 \mathrm{CE}$-STC 31/1984-, derecho del que carecen los miembros de la Guardia Civil. Esta será razonablemente una de las funciones que desarrollará el Consejo Asesor de Personal, recientemente creado por el Real Decreto 4/2002, de 11 de enero. No hay que olvidar que, como ha señalado el Tribunal Constitucional en relación con las condiciones de trabajo o del alcance de la remuneración, no son lícitas ni las discriminaciones por sexo, ni las deducibles de cualquier circunstancia personal o social -STC 31/1984-.

b) El derecho a la salud y a la seguridad en el trabajo.

Como hemos señalado, toda persona tiene derecho a recibir una asistencia sanitaria, dentro de las prestaciones de la seguridad social, no sólo a partir de los principios rectores de la política social y económica arts. 41 y $43 \mathrm{CE}$ - sino en virtud del propio derecho a la vida - art. $15 \mathrm{CE}-$ y de la vertiente objetiva de este derecho fundamental. El Real Decreto Legislativo 4/2000, de 23 de junio, por el que se aprueba el texto refundido de la Ley de Seguridad Social de los Funcionarios Civiles del Estado establece que las prestaciones sanitarias las gestiona MUFACE para los funcionarios civiles e ISFAS para el personal militar. La Ley 42/1999, de 25 de noviembre, que aprueba el Estatuto de Personal de la Guardia Civil señala que los servicios de sanidad de la Guardia Civil están incluidos en la Sanidad Militar - art. 96.2-. El Real Decreto Legislativo 1/2000 ha establecido en su art. 3 que quedan obligatoriamente incluidos dentro del campo de aplicación del Régimen Especial de la Seguridad Social para las Fuerzas Armadas los militares de carrera de la Guardia Civil. Este mismo Real Decreto Legislativo ha establecido que la prestación sanitaria del ISFAS pueda hacerse estableciendo conciertos "con la Sanidad Militar y con otras instituciones públicas y privadas" - art. 14-. A partir de la profesionalización del ejército y de la consiguiente reducción del mismo, ha sido necesario adecuar la dimensión de la red hospitalaria militar a las nuevas necesidades, lo que ha permitido a los militares -y por tanto a los Guardias Civiles - la posibilidad de optar como tienen el resto de los funcionarios entre la sanidad pública y la sanidad privada78.

78 En la actualidad el total de beneficiarios de asistencia sanitaria en la Guardia Civil son 320.904: 96.171 - viudas y retirados - y 224.733 -activo y reserva -. La elección de la prestạción sanitaria da como resultado el siguiente cuadro: 23.816 están en el Instituto Nacional de la Seguridad Social, 10.652 en Sanidad Militar, 112.270 en ASISA, 133.992 en ADESLAS, 17.133 en Cajasalud, $y$ en otras entidades 23.041. 
No obstante, el hecho que esta prestación esté externalizada no debe eximir a la Guardia Civil del deber de seguimiento y supervisión de la calidad de la asistencia sanitaria de sus miembros cuando no sea prestada por la sanidad pública. En todo caso, la Sanidad Militar en la Guardia Civil sigue desempeñando funciones importantes como la realización de campañas y programas para mejorar la medicina asistencial y preventiva, la promoción de la salud a través de vacunaciones, control de epidemias y de enfermedades transmisibles, el control periódico del personal sometido a riesgos especiales, las prevención de intoxicaciones alimentarias, el control de las bajas y la elaboración de planes para la reducción del absentismo laboral -al que más adelante nos referiremos-y la colaboración en los procesos de selección del personal 79 .

Las prestaciones del Instituto Social de las Fuerzas Armadas son de dos tipos: prestaciones obligatorias y prestaciones eventuales. Las prestaciones obligatorias, además de la asistencia sanitaria, son los subsidios temporales de incapacidad transitoria e invalidez provisional, las prestaciones recuperadoras por incapacidad y para la remuneración de la persona encargada de la asistencia a un gran inválido, las indemnizaciones por lesiones, mutilaciones o deformidades causadas en acto de servicio o por enfermedad profesional, los servicios sociales y la asistencia social, y los subsidios de nupcialidad y natalidad. Las prestaciones eventuales son las pensiones complementarias de las ordinarias de clases pasivas, en todas sus modalidades.

Si el derecho a la retribución es una parte esencial del derecho al trabajo, también lo son las políticas que garanticen la formación y la readaptación profesionales, la seguridad y la higiene en el trabajo y el descanso necesario, a través de la limitación de la jornada laboral, las vacaciones periódicas retribuidas y la promoción de centros adecuados - art. $40 \mathrm{CE}-$. Estos son principios de política económica, laboral y social que han recibido un progresivo desarrollo legislativo.

La Directiva 89/391/CEE del Consejo de la Unión Europea, relativa a la aplicación de medidas para promover la mejora de la seguridad y de la salud de los trabajadores en el trabajo 80 , incluye principios generales relativos a la prevención de los riesgos profesionales y la protección de la seguridad y de la salud, la eliminación de los factores de riesgo y accidente, la información, la consulta, la participación equilibrada de conformidad

79 Cfr. J. A. LÓPEZ LOPEZ, "Los derechos sociales en la Guardia Civil", in voce.

80 DOL 29 de junio de 1989, núm. 183. 
con las legislaciones y los usos nacionales, la formación de los trabajadores y de sus representantes, así como las líneas generales para la aplicación de estos principios. Esta Directiva se aplica a todos los sectores de actividades públicas o privadas. Ahora bien, señala - art. 2.2- que la presente directiva "no será de aplicación cuando se opongan a ello de manera concluyente las particularidades inherentes a determinadas actividades específicas de la función pública, por ejemplo, en las fuerzas armadas o la policía, o a determinadas actividades específicas en los servicios de protección civil». No obstante, en este caso "será preciso velar para que la seguridad y la salud de los trabajadores queden aseguradas en la medida de lo posible, habida cuenta los objetivos de la presente Directivan.

Por su carácter general, la mayor parte de las disposiciones de la Directiva no eran susceptibles de aplicación directa, ya que faltaban los requisitos para ello; la Directiva no era incondicionada ni suficientemente precisa y detallada 81 . Esta Directiva fue incorporada a nuestro ordenamiento jurídico por la Ley 31/1995, de 8 de noviembre, de Prevención de Riesgos Laborales. Esta Ley, además de responder a un mandato constitucional y transponer la Directiva Comunitaria, pone término a la falta de una visión unitaria en la política de prevención de riesgos laborales, debido a la dispersión normativa previa, fruto de la acumulación en el tiempo de normas de muy diverso rango y orientación, a la vez que regula situaciones nuevas que demandan las profundas transformaciones experimentadas en los centros de trabajo. La política de prevención de riesgos laborales, que articula el conjunto de actuaciones de los poderes públicos dirigidas a la promoción de la mejora de las condiciones de trabajo para elevar el nivel de protección de la salud y de la seguridad de los trabajadores, se desarrolla así a través de los principios de eficacia, coordinación y participación, ordenando así tanto la actividad de las Administraciones públicas con competencia en la materia preventiva, como la necesaria participación de empresarios y trabajadores, a través de sus organizaciones representativas.

La Ley persigue, ante todo, la prevención, por lo que su articulación no puede descansar únicamente en la ordenación de las obligaciones y responsabilidades de los actores directamente relacionados con el hecho laboral. El propósito de fomentar una auténtica cultura preventiva median-

81 Cfr: A. Montoya y J. PIZA, Curso de seguridad y salud en el trabajo, McGrawHill, Madrid, 2000 pág. 40. La política comunitaria en el ámbito de la salud y la seguridad en el trabajo se puede ver en el / Congreso Internacional de Prevención de Riesgos Laborales, Ayuntamiento de Madrid, 1997, págs. 91-152. 
te la promoción de la mejora de la educación involucra a la sociedad en su conjunto y constituye uno de los objetivos básicos de esta Ley82.

No obstante, la experiencia acumulada desde la entrada en vigor de la Ley 31/1995, de 8 de noviembre ha permitido constatar la existencia de ciertos problemas que dificultan su aplicación como la de determinadas insuficiencias en su contenido, que se manifiestan en términos de accidentes de trabajo y en la subsistencia de índices de siniestralidad laboral indeseados que reclaman actuaciones profundas y ágiles. La Mesa de Diálogo Social en materia de Prevención de Riesgos Laborales, donde están presentes las organizaciones empresariales y sindicales, así como la Conferencia Sectorial de Asuntos Laborales que reúne al Gobierno y a las Comunidades Autónomas han puesto de manifiesto una deficiente incorporación del nuevo modelo de prevención y una falta de integración de la prevención en la empresa, que se evidencia en muchas ocasiones en un cumplimiento más formal que eficiente de la normativa. Además, es necesario adecuar la normativa de prevención de riesgos laborales a las nuevas formas de organización del trabajo, en especial a las diversas formas de subcontratación. Esto ha dado lugar a un Proyecto de Ley de reforma del marco normativo de prevención de riesgos laborales, que presumiblemente será aprobado en este periodo legislativo en la Comisión de Política Social y Empleo83.

La Ley 31/1995, de 8 de noviembre, de Prevención de Riesgos Laborales incluye en su ámbito de aplicación, además de las relaciones laborales, aquellas otras de carácter administrativo o estatutario del personal civil al servicio de las Administraciones Públicas, con las particularidades contempladas en el propio texto legal o en las normas de desarroIlo. Al igual que la Directiva, la Ley excluye de las medidas que regula todas aquellas actividades cuyas particularidades lo impidan en el ámbito de las funciones públicas. Entre otras, cita las de policía, seguridad, resguardo aduanero y los servicios operativos de protección civil y peritaje forense en los casos de grave riesgo, catástrofe y calamidad pública, todas ellas incluidas entré las funciones asignadas a la Guardia Civil por la Ley Orgánica 2/1986, de 13 de marzo, de Fuerzas y Cuerpos de Seguridad. Sin embargo, a continuación dispone que la normativa específica que se dicte

82 La Ley ha sido analizada en distintos seminarios organizados por la Universidad Internacional Menéndez y Pelayo y el Ministerio de Salud Carlos III. Es de destacar los seminarios Las normas de seguridad y salud en el trabajo, Santander, 1997 y Prevención de riegos de las mujeres en el trabajo, Santander, 1998.

83 BOCG VII Legislatura. Serie A, 23 de julio de 2003, núm. 167-1. 
para la protección de la seguridad y de la salud de los trabajadores que prestan servicio en las indicadas actividades habrá de inspirarse en la propia Ley.

Tanto la Ley de Prevención de Riesgos Laborales como las disposiciones que la desarrollan tienen vocación de universalidad e integración, lo que en el ámbito de las Administraciones Públicas supone, como expone el preámbulo del Real Decreto de adaptación de la legíslación de riesgos laborales a la Administración General del Estado, considerar la prevención como una actuación única, indiferenciada y coordinada que debe llegar a todos los empleados públicos sin distinción del régimen jurídico que rija su relación de servicio, y se traduce en una planificación de la actividad preventiva integral e integrada en el conjunto de actividades y decisiones de la citada Administración.

La Ley 31/1995, de 8 de noviembre, de Prevención de Riegos Laborales tiene una vocación de universalidad, ya que trata de abordar de manera global y coherente el conjunto de problemas derivados de los riesgos relacionados con el trabajo, cualquiera que sea su ámbito. De hecho, uno de los elementos novedosos de esta Ley, como señala su Exposición de Motivos, es su aplicación en el ámbito de las Administraciones Públicas, razón por la cual la Ley no sólo posee el carácter de legislación laboral sino que constituye, en sus aspectos fundamentales, norma básica del régimen estatutario de los funcionarios públicos, dictada al amparo de lo dispuesto en el art. $149.1 .18^{\circ}$ de la Constitución -Disposición Adicional $3^{\mathrm{a}}-$. De esta forma, el ámbito de aplicación de la Ley incluye tanto a trabajadores vinculados con la Administración a través de una relación laboral, como al personal civil con relación administrativa o estatutaria con las Administraciones Públicas.

No obstante, la Ley establece un conjunto de exclusiones en el ámbito de la función pública que abarca a determinadas actividades de policía, seguridad, resguardo aduanero, peritaje forense y protección civil, cuando existan particularidades que impidan la aplicación de la ley, que en todo caso debe inspirar la normativa específica que se dicte para salvaguardar la seguridad y la salud de los trabajadores en dichas actividades - art. 3.2-. Existen diversas peculiaridades en las Administraciones públicas que justificaron la elaboración de una normativa especial de los derechos de participación y representación, la organización de los recursos necesarios para el desarrollo de las actividades preventivas, etc., y que se materializó en el Real Decreto 1488/1998, de 10 de julio.

Las funciones asignadas a la Guardia Civil en la Ley Orgánica de Fuerzas y Cuerpos de Seguridad presentan unas características específicas que permiten, conforme a la Directiva y a la Ley, su exclusión del ámbito 
de aplicación, pues exigen el cumplimiento de su misión de proteger el libre ejercicio de los derechos y libertades y garantizar la seguridad ciudadana, aún reconociendo la posibilidad de que en tales actuaciones puedan existir graves riesgos para su vida o integridad física. Por ello, es necesario identificar las actividades encomendadas a la Guardia Civil cuyas particularidades se opongan de manera concluyente tanto a la aplicación del régimen general de la Ley como de su adaptación para la Administración General del Estado, sobre protección de riesgos laborales. A la vez, es necesario diseñar un conjunto de normas singulares que, inspiradas en la Ley 31/1995, permitan mejorar en la medida de lo posible la seguridad y la salud de los miembros de este Cuerpo de Seguridad del Estado. Estas normas deben de tener presente la naturaleza militar de la Guardia Civil. La Guardia Civil depende del Ministro de Defensa en el cumplimiento de las misiones de carácter militar que por su naturaleza se le encomienden, dependencia que se transforma en exclusiva en tiempo de guerra y durante el estado de sitio, por lo que la regulación normativa que se diseñe ha de excluir las actividades que en estos supuestos se realicen y que habrá de someterse a las normas que para tales casos se establezcan.

Sin embargo, nada impide que las funciones policiales que desarrolla la Guardia Civil y que son compartidas con otro Cuerpo de Seguridad de naturaleza civil puedan considerarse incluidas en el ámbito subjetivo de aplicación tanto de la Directiva como de la Ley 31/1995. Al contrario, algunas de las funciones que realizan los miembros de la Guardia Civil no presentan características exclusivas de las actividades de policía, seguridad, resguardo aduanero y servicios operativos de protección civil, por lo que han de someterse al régimen general de la propia Ley $y$ de las normas que la desarrollan, con las particularidades que en su caso sea preciso establecer. Hay que tener presente, además, la existencia de numerosas disposiciones internas del propio Instituto Armado, que contienen valiosas medidas en materia de prevención de riesgos derivados de las funciones que sus miembros desempeñan.

En todo caso, adaptaciones normativas al margen, deben tener especial importancia en la Guardia Civil las políticas de prevención y salud en el trabajo. El incremento en los últimos años del número de bajas por enfermedad -muchas de ellas por cuadros de estrés o depresión ${ }^{84}-$ exige un

84 Hay 3.500 Guardias Civiles en baja laboral por motivos psicológicos. Según datos del Servicio de Asistencia Sanitaria de la Guardia Civil, el número de Guardias Civiles publicados en BOD/BOC excluidos total por pérdida de condiciones psicofísicas por psiquiatría era de 135 en 1998, 226 en 1999, 386 en 2000 y 441 en 2001. 
estudio detenido, especialmente por la consideración de la Guardia Civil como un instituto armado. Sin duda, muchas de estas bajas médicas representan una forma de protesta o una medida de presión. En cualquier caso es necesario mejorar los reconocimientos médicos y las distintas pruebas psicológicas y físicas para poder detectar mejor las insuficiencias en las condiciones psicofísicas de los guardias civiles, de forma que se pueda garantizar ante la sociedad que los guardias civiles tienen la capacidad psicofísica para ocupar los diferentes destinos, lo que redundará en un beneficio para la seguridad de los ciudadanos y de los propios guardias civiles ${ }^{85}$.

En relación con la seguridad y la salud en el trabajo, y más en concreto, con el tratamiento de la pérdida de aptitudes psicofísicas, se ha producido una interesante y compleja evolución, influenciada por la doble condición civil y militar de la Guardia Civil. La configuración de la Guardia Civil como un cuerpo policial hacía que la entonces llamada inutilidad física pudiera dar lugar al retiro o al pase a la situación de reserva activa que más adelante pasó a denominarse reserva-creada por la Ley 20/1981, según que la enfermedad o lesión estuviera incluida en el correspondiente cuadro de inutilidades con el dictamen preceptivo de los tribunales médicos militares. El expediente de inutilidad física podía iniciarse cuando se tuviese conocimiento de la misma, por ser evidente. Era de aplicación en ese momento la Ley Orgánica 2/1986, de 13 de marzo, de Fuerzas y Cuerpos de Seguridad que determinó que los expedientes fueran tramitados según las normas dictadas para las Fuerzas Armadas 86 .

La ley 17/1989, de 19 de julio, estableció un nuevo régimen de personal para las Fuerzas Armadas, que, a partir de la remisión normativa ya citada de la Ley Orgánica 2/1986, era de aplicación a la Guardia Civil. En su artículo 95 recogía la posibilidad de que como consecuencia de reconocimientos médicos o de las pruebas físicas que establecía se pudiera iniciar un expediente de declaración de no aptitud para el servicio por insuficiencia de condiciones psicofísicas, que sería apreciado por los tribunales competentes, dando lugar a la declaración de inutilidad permanente para el servicio o a una limitación para ocupar determinados destinos 87 . Sin

85 Cfr. E. Blasco y F. Diezz Alcantud, "La Guardia Civil del Siglo XXI", en I. Cosidó (coord.), La Guardia Civil más allá del año 2000, cit. pág. 236.

86 Orden del Ministerio de Defensa núm. 21/1985, de 10 de abril.

87 El art. 95 de la Ley 17/1989, 19 julio, en relación con las evaluaciones para determinar si existe insuficiencia de condiciones psicofísicas a efectos de pase a retiro ó de limitación para ocupar determinados destinos, señalaba: "Como consecuencia de los reconocimientos médicos o de las pruebas físicas a que se hace referencia en el articulo 70 de la presente Ley, se podrá iniciar expediente de declaración de no aptitud para 
embargo, las normas que la desarrollan excluyeron de su ámbito de aplicación al personal de la Guardia Civil, que seguiría rigiéndose por las disposiciones hasta entonces en vigor. Así, la norma reguladora de los expedientes de pérdida de la aptitud psicofísica, el Real Decreto 1385/1990, de 8 de noviembre, de adquisición y pérdida de la condición de militar y de situaciones administrativas del personal militar, en su disposición transitoria 13, decía: "Hasta tanto no se desarrolle reglamentariamente el régimen jurídico sobre la adquisición y pérdida de la condición de militar y de situaciones administrativas del personal perteneciente al Cuerpo de la Guardia Civil, seguirá rigiéndose por las disposiciones hasta ahora en vigor».

Por ello fue preciso elaborar la Ley $28 / 1994$, de 18 de octubre, de Régimen del Personal de la Guardia Civil, de muy escaso contenido específico y de remisión casi general a la citada Ley $17 / 198988$. Concretamente y por lo que se refiere a los expedientes de pérdida de condiciones psicofísicas se remite al artículo 95 de dicha Ley, pero con la posibilidad de permanecer hasta dos años en activo (pérdida temporal de condiciones psicofísicas) hasta el inicio del expediente ${ }^{89}$. La pérdida definitiva de condi-

el servicio por insuficiencia de condiciones psicofísicas; que será apreciada por los tribunales competentes y podrá dar lugar a la declaración de inutilidad permanente para el servicio o a una limitación para ocupar determinados destinos. El expediente será elevado al Jefe de Estado Mayor del Ejército correspondiente, el cual propondrá al Ministro de Defensa la resolución que proceda".

88 El art. 8 de la Ley 28/1994, 18 octubre, derogada por la Ley 42/1999, de 25 de noviembre, de Régimen del Personal del Cuerpo de la Guardia Civil, señalaba en relación a la situación de servicio activo que "[c] uando el personal de la Guardia Civil, como consecuencia de lesión o enfermedad, carezca temporalmente de condiciones psicofísicas de aptitud para el servicio podrá permanecer en situación de servicio activo, por un período máximo de dos años. De continuar la incapacidad se iniciará el expediente que se determine en el artículo 95 de la Ley 17/1989 Reguladora del Régimen del Personal Militar Profesional. El expediente será elevado al Director general de la Guardia Civil, el cual propondrá al Ministro de Defensa la resolución que proceda".

89 Esto ha sido desarrollado por el Real Decreto 1429/1997, de 15 de septiembre, que aprobaba el Reglamento general de adquisición y pérdida de la condición de militar de carrera del Cuerpo de la Guardia Civil y de situaciones administrativas del personal de dicho Cuerpo. Así, en el art. 14 "Situación de servicio activo", se señala que "[e]l personal del Cuerpo de la Guardia Civil estará en situación de servicio activo cuando ocupe destinos en Unidades, Centros y Dependencias de la Dirección General de la Guardia Civil, en los Ministerios del Interior y de Defensa y, cuando se trate de puestos relacionados con las misiones que tienen asignadas, en la Presidencia del Gobierno, en otros Departamentos ministeriales u Organos del Estado y en Organismo internacionales. En relación a la pérdida temporal de condiciones psicofísicas se establece que cuando un guardia civil, como consecuencia de lesión o enfermedad, que no resulte irreversible, carezca temporalmente de condiciones psicofísicas de aptitud para el servicio, "podrá 
ciones psicofísicas determinará el pase a retiro o una limitación para ocupar determinados destinos. La vigente Ley 42/1999, de 25 de noviembre, que aprueba el Estatuto de Personal del Cuerpo, si bien no supone un cambio normativo acusado, sí contiene dos precisiones importantes a la hora de instruir un expediente de pérdida de aptitudes psicofísicas: la iniciación inmediata del expediente cuando se presuma que la insuficiencia es definitiva; $y$ el cese en el destino del expedientado, si lo tuviere ${ }^{90}$.

permanecer en la situación de servicio activo por un período máximo de dos años, transcurrido el cual pasará a la situación de disponible; iniciándose el expediente de declaración de no aptitud para el servicio por insuficiencia de condiciones psicofísicas". El expediente deberá estar finalizado en el plazo máximo de seis meses desde la fecha en que pasó a la situación de disponible. "En el caso de que la pérdida temporal de condiciones psicofísicas se convierta en definitiva como consecuencia de un expediente de aptitud psicofísica iniciado a instancia del interesado o de su Jefe de Unidad o Centro o Dependencia, se estará a lo que declaren los Tribunales competentes, que podrá dar lugar al pase a retiro o a una limitación para ocupar determinados destinos". "El plazo máximo de dos años de carencia temporal de condiciones psicofísicas de aptitud para el servicio se computará a partir del segundo mes consecutivo o tercero alterno en el plazo de un año en que, por enfermedad o lesión, se esté recibiendo asistencia sanitaria sin poder prestar servicio. Pasados cualquiera de estos últimos plazos y de continuar las mismas circunstancias se podrá cesar en el destino por interés del servicio".

90 Así, el art. 49 de la Ley 42/1999, de 25 de noviembre, de régimen de personal del cuerpo de la Guardia Civil señala en su art. 49 "Expediente de aptitud psicofísica": "En el expediente de aptitud psicofísica figurarán los resultados de los reconocimientos médi$\cos$ y de las pruebas psicológicas y físicas que se realizaren con el contenido y periodicidad que se establezca reglamentariamente según el empleo, Escala, edad y circunstancias personales, o en cualquier momento a iniciativa fundamentada del propio interesado o del jefe de su unidad, centro u organismo. También figurarán todos aquellos que se realicen con objeto de determinar si existe insuficiencia de condiciones psicofísicas, a los efectos establecidos en la presente Ley. Los reconocimientos y pruebas podrán comprender análisis y comprobaciones con carácter obligatorio, encaminados a detectar los estados de intoxicación etílica y el consumo de drogas tóxicas o sustancias similares. Los resultados de los reconocimientos médicos y pruebas psicológicas quedaren salvaguardados por el grado de confidencialidad que la legislación en materia sanitaria les atribuya".

En el art. 55 de la misma Ley - "Evaluaciones extraordinarias para determinar si existe insuficiencia de condiciones psicofísicas" - se indica que como consecuencia de los reconocimientos médicos o de las pruebas psicológicas y físicas a las que se refiere el artículo 49, así como en los supuestos previstos en el artículo 97, ambos de la presente Ley, se podrá iniciar un expediente para determinar si existe insuficiencia de condiciones psicofísicas, a efectos de la limitación para ocupar determinados destinos o del pase a retiro".

En el artículo 97 - "Insuficiencia temporal de condiciones psicofísicas - se indica que "al guardia civil que, como consecuencia de los reconocimientos médicos y pruebas físicas a lo que se refiere el artículo 49 de esta Ley, le sea apreciada una insuficiencia de condiciones psicofísicas para el servicio, motivada por lesión o enfermedad, que no resulte irreversible, permanecerá en situación administrativa en la que se encuentre. 
La demora casi general de dos años para iniciar el expediente de insuficiencia psicofísica, unido al hecho de que los tribunales médicos militares consideraban en sus dictámenes que la lesión o enfermedad era temporal y procedía una nueva revisión, ha conllevado la acumulación de muchos expedientes tramitados al amparo del Real Decreto 1429/1997 con otros expedientes iniciados inmediatamente a partir de la entrada en vigor de la Ley 42/1999, cuando se presumía que la incapacidad era definitiva. En otros casos, la limitación para ocupar determinados destinos produjo efectos similares a la demora de dos años por incapacidad temporal, pues el agravamiento de la lesión o enfermedad llevó a la incoación del oportuno expediente de inutilidad para el servicio. Aunque el Reglamento establece un plazo de seis meses para la resolución del expediente, la resolución de los expedientes se ha dilatado habitualmente hasta los dos años, debido a la gran cantidad de expedientes acumulados en el Ministerio de Defensa y a los recursos contra dictámenes médico-militares que pretendian obtener una declaración de que la inutilidad se produjo en acto de servicio.

Hay que señalar especialmente la pérdida de retribuciones que los Guardias Civiles tienen en esta situación de interinidad. Así, la incoación de un expediente lleva aparejada la pérdida de destino con la consiguiente pérdida del complemento específico y del complemento de productividad, lo que hace muy perjudicial para el Guardia Civil el retraso en la tramitación del expediente, ya que la pensión de retiro - que en caso de inutilidad se fija teniendo en cuenta los años de servicio que podrían haberse acumulado hasta cumplir la edad de retiro- no es sensiblemente inferior, e incluso es superior en algunos casos, sobre todo en el empleo de Guardia Civil, a las retribuciones que se perciben en las situaciones de reserva y de servicio activo sin destino.

Lo expuesto obliga a plantearse la aprobación de una normativa específica que regule la aptitud psicofísica del personal del cuerpo de la Guardia civil, que desarrolle los preceptos ya señalados en la Ley 42/1999. Esta regulación tiene que establecer los distintos niveles de aptitud psicofísica, dada las distintas actividades que tiene asignadas este Cuerpo, y la fijación de órganos médico-periciales y de cuadros de condiciones psicofísicas específicos. Todo jefe debe poder solicitar el reconocimiento médico extraordinario de sus subordinados si llega a apreciar indicios que así lo

En el momento en que la insuficiencia citada en el apartado anterior se presuma definitiva 0 , en todo caso, transcurrido un período de dos años desde que le fue aprecia$\mathrm{da}$, se iniciará el expediente que se regula en el artículo 55 de esta Ley. El afectado cesará en su destino si lo tuviere y mantendrá la misma situación administrativa hasta la finalización del referido expediente". 
aconsejen. Es necesario también plantearse la necesidad de un Servicio de Asistencia Sanitaria y de un Servicio de Psicología en la Guardia Civil. No parece aconsejable depender de los Tribunales médicos militares, por lo que puede plantearse la existencia de tribunales médicos propios de la Guardia Civil o el sometimiento al régimen general de la Seguridad Social. Si es más factible la creación del Servicio de Prevención de Riesgos Laborales, con la participación en este caso no de los Sindicatos pero sí del Consejo Asesor de la Guardia Civil.

La configuración de la Guardia Civil como un Instituto Armado de naturaleza militar ha determinado que la Constitución Española y la Ley Orgánica de Libertad Sindical excluyan a sus miembros del ejercicio del derecho de sindicación. Por ello, la participación de los miembros del cuerpo en la planificación, programación, organización y control de la gestión relacionada con la mejora de las condiciones de trabajo y la protección de la seguridad y salud de los trabajadores, configurada por la Ley 31/1995 como un principio básico de la política de prevención de riesgos laborales, habrá de realizarse por otros conductos distintos a las organizaciones sindicales más representativas.

Es en este aspecto donde también adquiere gran importancia la creación del Consejo Asesor de Personal del Cuerpo de la Guardia Civil, cuya composición, funcionamiento y procedimiento de elección fueron establecidos por el Real Decreto 4/2002, de 11 de enero. Por las funciones que tiene asignadas este órgano asesor puede constituirse en el medio para hacer llegar a los órganos específicos que se establecen las inquietudes de los guardias civiles en materia de prevención de riesgos laborales $y$ de salud en el trabajo.

c) El derecho a la vivienda: protección a la familia, parejas de hecho y prohibición de discriminación.

Si como hemos señalado la eficacia de los principios rectores de la política social y económica está en manos del legislador, hay que señalar que la Ley 30/1984, de 2 de agosto, de Medidas para la Reforma de la Función Pública ha establecido para los funcionarios un conjunto de derechos, de carácter más bien programático, a recibir una adecuada asistencia social, a través del fomento de la construcción de viviendas, residencias de verano, instalaciones deportivas, etc.

Como sabemos, el art. 47 CE señala que todos los españoles «tienen derecho a disfrutar de una vivienda digna y adecuada". Corresponde a los poderes públicos promover las condiciones necesarias y establecer las normas pertinentes para hacer efectivo este derecho. Como ya hemos 
señalado, nos encontramos especialmente en este caso con un principio rector de la política social y económica, que requiere un desarrollo legislativo para poder ser alegado ante los Tribunales. Como ha señalado el Tribunal Constitucional, la política de vivienda, junto a su dimensión estrictamente económica, debe tener un señalado acento social -STC 152/1998-.

En el caso de la Guardia Civil esta cuestión es especialmente importante ya que no sólo se trata de promover un derecho a través de la acción social pública, sino también de garantizar el cumplimiento de los servicios en pueblos y zonas costeras donde es difícil acceder a la vivienda, por su elevado precio o por la escasez de las mismas. Esto lleva a la obligación de facilitar, dentro de lo posible, una vivienda a los miembros de la Guardia Civil, teniendo en cuenta la movilidad geográfica de su personal. Esto ha dado lugar a los llamados pabellones o casas-cuartel de la Guardia Civil. Hay que tener en cuenta, no obstante, la afectación del derecho a la intimidad que se produce al habitar el guardia civil con su familia en una casa cuartel. En ocasiones, las casas-cuartel se han convertido en un elemento clave de la dependencia del individuo hacia el grupo y del control del guardia civil por parte del mando, una forma de tener a sus miembros más disponibles. El escenario mejor sería que los Guardias Civiles tuvieran una retribución económica adecuada que les permitiera una mayor accesibilidad a la vivienda sin necesidad de habitar en las casas-cuartel.

La regulación de los pabellones consideraba que éstos no eran estrictamente una acción pública directamente encaminada a la protección a la familia, sino a facilitar el cumplimiento del servicio, por lo que en el pasado habia sido posible adjudicar pabellones a todo el personal, cualquiera que fuera su estado civil. Esto se realizó ya a través de la Orden General núm. 54, de 8 de agosto de 1994, de Regulación de Pabellones en la Guardia Civil91. Con ella se consiguió, por un lado, suprimir la desigualdad de trato del personal soltero sin familiares a su cargo, $y$, por otro, potenciar el segundo factor determinante de la razón de ser de los pabellones, que es el servicio. La Orden antes citada sirvió además para adecuar la regulación a la incorporación de la mujer a la Guardia Civil y a la posibilidad de matrimonio entre componentes del Cuerpo, además de para equiparar el matrimonio con las relaciones análogas de afectividad.

En este campo, la Guardia Civil tiene planteados distintos retos: uno de ellos es, sin duda, la necesaria inversión en el Capítulo VI en las casas-

91 Esta Orden modificó la Orden General núm. 15, de 5 de febrero de 1988. 
cuartel para que éstas siempre sean viviendas dignas. Es imprescindible mejorar la calidad de los pabellones ya que algunos son antiguos o se encuentran en mal estado92. Además, la Guardia Civil se ha visto en la necesidad de garantizar que en la adjudicación de las casas, como acción de los poderes públicos, estén presentes dos principios. El primero de ellos es el de la protección a la familia, especialmente a la familia numerosa, ya que la familia es un bien constitucional. Así, el primer principio rector de la política social y económica que se encuentra en el Capítulo III delTítulo I es la afirmación de que los poderes públicos - la Guardia Civil no puede ser una excepción - asegurarán la protección social, económica y jurídica a la familia - art. 39.1 CE- La importancia de la acción pública protectora de la familia numerosa obedece tanto a una preocupación por el incremento de la natalidad en nuestro pais como a principios e imperativos de justicia social, pues el número de hijos puede constituir y de hecho en ocasiones genera dificultades añadidas para el acceso, por parte de sus miembros, a los bienes económicos, sociales y culturales. Se ha desarrollado asi una política de apoyo a la familia a través de medidas fiscales, de la mejora de las prestaciones de la Seguridad Social por hijos a cargo, de un trato preferente a la familia numerosa para la adjudicación de viviendas de propiedad o protección oficial, de la mejora en el régimen de financiación de las mismas, de ventajas fiscales y para el acceso a la enseñanza, y de las ayudas económicas a la natalidad, etc ${ }^{93}$.

El segundo criterio que ha de tenerse en cuenta en la adjudicación de viviendas militares es la prohibición de discriminación, especialmente ante algunas uniones de hecho distintas al matrimonio y donde también conviven niños, $y$ ante las uniones de hecho o libres de personas del mismo sexo ${ }^{94}$. Así, el art. $14 \mathrm{CE}$ señala que los españoles son iguales ante ley, sin que pueda prevalecer discriminación alguna por razón de nacimiento, raza, sexo, religión, opinión o cualquier otra condición o circunstancia personal o social. Además, el propio art. $39 \mathrm{CE}$ obliga a los poderes públicos a la pro-

92 En la encuesta que se pasó a los miembros de la Guardia Civil se constataba que la deficiencia más grave de los pabellones era la antigüedad y el mal estado de conservación.

93 Cfr. el Plan Integral de Apoyo a la Familia, de 8 de noviembre de 2001. Cfr. la Ley 8/1998, de 14 de abril, de ampliación del concepto de familia numerosa.

94 Cfr. J.V GAvIDIA, La unión libre, Tirant lo Blanch, Valencia, 1995. Más recientemente J. V. GAVIDIA, "Uniones homosexuales y concepto constitucional de matrimonio", REDC núm. 61, 2001, págs. 11-58; M. O. SÁnCHEZ MARTínez, "Constitución y parejas de hecho. El matrimonio y la pluralidad de estructuras familiares", REDC, núm. 58, 2000, págs. 45-70. 
tección integral de los hijos, iguales éstos ante la ley con independencia de su filiación y de las madres, cualquiera que sea su estado civil.

Así, la familia protegida constitucionalmente no es exclusivamente la fundada en el matrimonio. Existen otras uniones de hecho que merecen también protección. No obstante, como ha señalado el Tribunal Constitucional en la Sentencia 74/1997, un trato jurídico diferente de la familia matrimonial y de la no matrimonial no es incompatible con la igualdad jurídica y la prohibición de discriminación que la Constitución garantiza en el art. 14. El concepto constitucionalmente adecuado de familia debe incluir a la fundada en el matrimonio -STC 45/1985-, que debe merecer siempre un trato preferente sobre las uniones de hecho. El art. 39 CE no establece ni exige por sí solo una paridad de trato en todos los aspectos y órdenes de las uniones matrimoniales y las no matrimoniales -STC 184/1990-. Pero la exclusión de derechos de quienes hayan vivido more uxorio frente a los reconocidos a los conyuges no puede incurrir en arbitrariedad -STC 222/1992-.

En este marco, tiene especial importancia la Orden General número 20 , de 11 de diciembre de 2002, que modifica la Orden General núm. 54, de 8 de agosto de 1994, antes citada, sobre regulación de pabellones en la Guardia Civil. Por una parte, la Guardia Civil trata de contribuir a estos objetivos de política social mediante la concesión a las familias numerosas de un derecho preferente para la adjudicación de algunos de los pabellones disponibles en las distintas Unidades del Cuerpo, haciéndolo compatible con los derechos de los demás miembros de la Institución. Por otra parte, la regulación de pabellones trata de tener en cuenta las distintas formas de unión en convivencia de carácter estable al margen del matrimonio que se dan en la sociedad actual ${ }^{95}$. Así, la la adjudicación de pabellones de Unidad se efectuará cuando hay más de un peticionario de cada grupo por el siguiente orden - art. 12.Uno-:

95 De esta forma, se modifica el art. 7 de la Orden General número 54, de 8 de agosto de 1994, de regulación de pabellones en la Guardia Civil, que queda redactado de la siguiente forma: "Tres. En el supuesto de matrimonio o convivencia de hecho en que ambos cónyuges o parejas de hecho tuvieran derecho a pabellón, se tendrán en cuenta las siguientes normas:

- El cónyuge o pareja de hecho de quien tuviera adjudicado pabellón de unidad, estando ambos destinados en la misma y teniendo ambos derecho a pabellón de igual categoria, no lo podrá solicitar, si bien continuará ocupando el pabellón asignado al otro cónyuge o pareja de hecho en el caso de que concurra en el adjudicatario alguno de los supuestos de cese en la ocupación. Si tuviera derecho a pabellón de distinta categoría podrá solicitarlo y de 
1. Personal designado para ocupar los destinos. De no existir pabellón en el momento de la solicitud se le adjudicará el primero de su categoría que quede vacante, por el orden en que aparecen relacionados en el citado Anexo.

2. Personal con familia numerosa a su cargo, sin que en ningún caso y por la utilización de esta preferencia pueda superarse la adjudicación de la tercera parte de cada categoría de pabellones.

3. Personal casado o formando pareja de hecho estable, con familiares a su cargo hasta el segundo grado de consanguinidad o afinidad.

4. Personal casado o formando pareja de hecho estable, y personal soltero, separado o divorciado con familiares a su cargo hasta el segundo grado de consanguinidad o afinidad.

5. Antigüedad en la petición.

6. Antigüedad del último destino a la Unidad.

7. Superior empleo y, dentro de un mismo empleo, mayor antigüedad.

8. El que menos tiempo hubiera disfrutado de pabellón desde su ingreso en el Cuerpo.

Igualmente se regula las personas autorizadas a vivir en pabellón - art. 16.Uno - : «Podrán habitar el pabellón el adjudicatario, su cónyuge o persona con la que forme pareja de hecho estable y los familiares de ambos hasta el segundo grado de parentesco. Para el resto de las personas se requerirá autorización escrita del mando que tenga facultad para la adjudicación. Dos. a) A los efectos de la presente Orden se considerará la existencia de pareja de hecho estable cuando, siendo ambos mayores de edad y no sujetos a vinculo matrimonial, se haya producido la convivencia

corresponderle su adjudicación ocuparán el de mayor categoría. Si cesaran en el derecho a la adjudicación de este pabellón, pasarán a ocupar el primer lugar en la relación de peticionarios para la categoría del que se desaloja o no se ocupa.

- E1 cónyuge o pareja de hecho de quien ocupa pabellón de cargo o unidad, perteneciendo ambos a distinta Unidad de la misma residencia, podrá solicitar pabellón, pero si por su turno le corresponde la adjudicación, tendrán que optar por uno de ellos. Si la opción se ejerce por el que se está ocupando, permanecerá, en la relación de peticionarios, en el lugar que ocupe en el momento de la opción". 
durante un período ininterrumpido de dos años, como mínimo, o se haya manifestado la voluntad de constituirla mediante escritura pública. b) En el caso de que un miembro de la pareja o ambos estén ligados por vínculo matrimonial, el tiempo de convivencia transcurrido hasta el momento en que el último de ellos obtenga la disolución, o en su caso la nulidad, se tendrá en cuenta en el cómputo de los dos años. c) Podrá acreditarse la existencia de pareja estable y el transcurso de los dos años de referencia, si no existiera escritura pública, mediante cualquiera de los medios de prueba admitidos en derecho, especialmente a través de certificado de convivencia, acta de notoriedad, documento judicial que acredite la convivencia, o inscripción en el registro de parejas de hecho correspondiente. La existencia de pareja de hecho estable será reconocida, sin más trámites, cuando se acredite documentalmente que existen hijos en común».

d) El derecho a la conciliación de la vida familiar y laboral.

Uno de los derechos sociales más importantes es el derecho a conciliar la vida familiar y la vida laboral96. A este aspecto se ha referido el Acuerdo del Consejo de Ministros por el que se aprueba el Acuerdo Administración-Sindicatos para el periodo 2003-2004 para la modernización y mejora de la Administración Pública97. La conciliación de la vida familiar con la vida laboral es un elemento esencial del desarrollo equilibrado de una sociedad democrática avanzada que tiene como un valor fundamental la igualdad de los ciudadanos. De la posibilidad de conciliar el trabajo con la vida familiar depende, en gran medida, la mayor incorporación de la mujer al mercado de trabajo 98 . Como afirma dicho Acuerdo, la

96 Ley 39/1999, de 5 de noviembre, para promover la conciliación de la vida familiar y laboral de las personas trabajadoras.

97 Cfr. la Resolución de 15 de noviembre de 2002 de la Secretaría de Estado para la Administración Pública, por la que se ordena la publicación del Acuerdo de Consejo de Ministros de 15 de noviembre de 2002 por el que se aprueba el Acuerdo Administración-Sindicatos para el periodo 2003-2004, para la modernización y mejora de la Administración Pública. Este Acuerdo está orientado principalmente a la calidad en la prestación de los servicios en el ámbito de la Administración, tanto en la Administración Central del Estado como en su Administración Periférica. Las políticas de calidad de los servicios públicos en la Guardia Civil ha sido estudiada por B. SALCEDO, “La gestión de la calidad en la Guardia Civil", Cuadernos de la Guardia Civil, núm. 22, 2000, págs. 133-158. En este artículo el autor analiza la adaptación posible de la Guardia Civil del Modelo Europeo de Excelencia -FOM-.

98 Real Decreto 1686/2000, de 6 de octubre, por el que se crea el Observatorio de la Igualdad de Oportunidades entre mujeres y hombres. 
ausencia de una política activa de conciliación que permita a trabajadores y trabajadoras la compatibilización del desarrollo de una carrera profesional y la culminación de sus aspiraciones laborales fundando una familia es profundamente negativo tanto para el conjunto de la sociedad, que sufre como expresión más evidente la baja natalidad, como para los trabajadores que se ven obligados a optar entre trabajo y familia, opción que, además, redunda en perjuicio de la propia organización que sufre al verse privada de trabajadores con alto potencial. Esta conciliación se desarrolla principalmente a través de la promoción de servicios de guardería y la potenciación de la prestación de servicios a tiempo parcial - la reducción de jornada por motivos familiares-.

La conciliación de la vida familiar con el trabajo es especialmente importante en la Guardia Civil. No tendría sentido haber facilitado la incorporación de la mujer a la Guardia Civil si no se facilitan los medios para poder hacer compatible el cumplimiento de los destinos con la vida familiar. No obstante, hay distintos factores propios de la actividad laboral de los guardias civiles que dificulta la conciliación de la vida familiar y la laboral, como la elevada movilidad geográfica de los miembros del cuerpo y la imprevisibilidad de muchas situaciones que requieren la presencia de la Guardia Civil.

Existen algunas medidas concretas que se pueden establecer para facilitar dicha conciliación. Destacaríamos, por ejemplo, que los mandos den a conocer de manera más anticipada los turnos, la protección a las embarazadas con destinos que no supongan riesgos y la adecuación de los cursos de promoción interna y de capacitación a la vida familiar de la mujer.

Dentro de este ámbito, cobra importancia la posibilidad de la apertura de guarderías en determinados centros de la Guardia Civil. Esto ya ha sido puesto en práctica por otros departamentos y Organismos en el ámbito de la Administración General del Estado Ministerio de Economía, Ministerio de Defensa, Ministerio de Fomento, Ministerio de Hacienda, etc- ${ }^{99}$. Otra posibilidad puede ser la subven-

99 Estas deben tener en cuenta la normativa especifica, en especial el Real Decreto 1004/1991, de 14 de junio, de Centros Docentes no universitarios, que regula los requisitos mínimos que deben reunir aquellos Centros que impartan enseñanzas de régimen general, y la Orden de 11 de octubre de 1994 por la que se regulan las titulaciones mínimas que deben poseer los Profesores de los centros privados de Educación Infantil y Primaria, y la normativa autonómica correspondiente, así como las Ordenanzas de los Ayuntamientos respectivos en materia de condiciones higiénico-sanitarias y técnicas de los centros de cuidado y recreo infantil. 
ción por parte de la Administración de una parte o de la totalidad del coste de la Guardería mediante un Plan de Acción Social, que tal vez se adecuaría más a la dispersión territorial de la Guardia Civil y evitaría desigualdades por zonas.

Un elemento importante que afecta a la vida familiar de los miembros de la Guardia Civil es la limitación de su lugar de residencia y desplazamiento y la obligación de localización. Esta limitación no sólo afecta a un derecho fundamental de los calificados como derechos de libertad, sino también al ejercicio de todos los derechos fundamentales y al bienestar social de la persona y de su familia. La elección del domicilio y de la residencia condiciona el desarrollo de la personalidad en libertad, no sólo del guardia civil sino también de su pareja, y la libre elección de centro educativo para los hijos - art. 27-.

El art. 19 CE señala que los españoles tienen derecho a elegir libremente su residencia y a circular por el territorio nacional. Inicialmente se trata de un derecho de libertad que impide las restricciones de los poderes públicos en ese ámbito ${ }^{100}$. Esto es, no obstante, compatible con la imposición de la residencia en el lugar de destino al funcionario que haya sido objeto de traslado forzoso por conveniencias del servicio debidamente justificadas ${ }^{101}$. La obligación de residencia en el lugar de destino se establece igualmente y con carácter general para los funcionarios públicos en el artículo 77 del texto articulado de la Ley de funcionarios civiles del Estado, aprobado por Real Decreto 315/1964, de 7 de febrero: "los funcionarios deberán residir en el término municipal donde radique la oficina, dependencia o lugar donde presten sus servicios".

El artículo 5.4 de la Ley Orgánica 2/1986, de 13 de marzo, de Fuerzas y Cuerpos de Seguridad establece el principio de dedicación profesional de los servidores del orden, a quienes impone el deber de estar en permanente disponibilidad para llevar a cabo sus funciones, pues han de intervenir siempre en cualquier tiempo y lugar, aunque no se hallen de servicio, en defensa de la Ley $y$ de la seguridad ciudadana. Para los guardias civiles, la obligación de residir en el lugar de su destino viene impuesta por el artículo 175 de las Reales Ordenanzas para las Fuerzas Armadas, que resulta aplicable por virtud de la remisión al ordenamiento militar efectuada por el art. 13.2 de la citada Ley Orgánica de Fuerzas y Cuerpos de Seguridad. Tal obligación, sin embargo, puede ser dispensada por circunstancias deter-

100 ATC 276/1983.

101 ATC 781/1985. 
minadas, autorizándose a los interesados a fijar su lugar habitual de residencia en un punto distinto, con la condición de que puedan cumplir adecuadamente todas sus obligaciones.

Esta cuestión ha sido abordada por la Orden General número 2, de 13 de enero de 2003. Como señala su Exposición de Motivos, desde el punto de vista de la seguridad ciudadana, la exigencia legal de que el guardia civil resida en la localidad donde radique su unidad de destino responde también a razones de proximidad e integración con la población en donde desempeña sus funciones, permitiéndole un mayor conocimiento de la demarcación territorial y de su problemática delincuencial, lo que redunda en un servicio más eficaz a los ciudadanos.

No obstante, esta Orden General ha supuesto una ampliación del grado de libertad de los Guardias Civiles para la elección de la residencia y del domicilio, que es una exigencia del propio principio pro libertate de máxima expansividad del derecho fundamental, cuando no exista una justificación clara en razones de interés público. Como señala esta Exposición de Motivos, "es un hecho contrastado que los actuales medios de transporte, públicos $y$ privados $y$ las nuevas infraestructuras en la red de carreteras y ferrocarril permiten que los desplazamientos y traslados sean más rápidos y seguros. Si a ello unimos los avances en la tecnología de comunicaciones (telefonía móvil, internet, correo electrónico, etc.), la dimensión de los conceptos distancia geográfica y comunicación adquieren un significado menor, posibilitando, de un lado, hacer compatible al personal la elección del lugar de residencia habitual con el adecuado cumplimiento de las obligaciones inherentes a su puesto de servicio, y de otro, el poder desplazarse por el territorio nacional cuando se hallare libre de servicio, siempre que se cumplan los requisitos de estar localizable y en condiciones de reintegrarse a su puesto con celeridad si las necesidades del servicio lo exigen. Estar localizable y, consiguientemente, la obligación de comunicar los datos precisos a la Unidad de destino, tiene un significado especial para el guardia civil por cuanto está vinculado al principio básico de actuación, antes mencionado, de dedicación profesional».

\section{ALGUNAS REFLEXIONES FINALES.}

La Guardia Civil está desarrollando un interesante proceso de reformas, tanto en su función de servicio a los ciudadanos como en su organización interna. Son muchas las nuevas funciones que la Guardia Civil realiza y que ha conllevado la creación de nuevos servicios como el Seprona 
- servicio de protección de la naturaleza - 102, el Servicio de Vigilancia en el Estrecho y los Equipos de Atención al Emigrante103, el Servicio Marítimo, los Grupos de Rescate e intervención en montaña, el Servicio de Delitos cibernéticos o los proyectos de cooperación internacional, de construcción de policías democráticas y de mantenimiento de la paz Guatemala, Bosnia, El Salvador, Mozambique-104.

Es de destacar también la reforma interna que se está acometiendo en la Guardia Civil en los últimos años. Podemos señalar por ejemplo la Ley 42/1999, de 25 de noviembre, que aprueba el Estatuto de Personal del Cuerpo, que se adecua a las necesidades de la institución como a los deseos de promoción profesional y que se encuentra ahora en fase de desarrollo reglamentario.

Especial mención merece la creación de un Consejo Asesor de Personal del Cuerpo de la Guardia Civil, a través del Real Decreto 4/2002, de 11 de noviembre. Este Consejo Asesor de Personal para la Guardia Civil es de composición plural y electiva, a diferencia del previsto en el Ministerio de Defensa ${ }^{105}$. Este Consejo, formado por Generales, jefes, oficiales, suboficiales y guardias, es un buen instrumento de participación de los Guardias Civiles que permite hacer llegar a los órganos específicos $y$, en especial, al Director General las inquietudes de los Guardias 106. El Consejo Asesor de la Guardia Civil es un órgano de asesoramiento al Director General de carácter no vinculante.

Se puede afirmar asi que la Guardia Civil ha sabido "adaptarse a los profundos cambios políticos, sociales culturales y económicos que se han producido en nuestro país desde la creación del Instituto, conservando al mismo tiempo lo mejor de sus orígenes, de sus principios y de sus tradi-

102 Cfr. J. Delgado, “Competencias y funciones de la Guardia Civil en la protección de la naturaleza", Cuadernos de la Guardia Civil, núm. 17, 1997, págs. 39-50; J. M. HERRERO LIMA, Seprona 1988-1998, Madrid, 1999.

103 Cfr. A. HinojosA, "La Guardia Civil y la inmigración: del SIVE al EDATI", Cuadernos de la Guardia Civil, núm. 27, 2002, págs. 99-108.

104 Cfr. R. CORTÉs, “La proyección internacional: la apuesta por Europa”, en I. Cosıdó (coord.), La Guardia Civil más allá del año 2000, cit. págs. 285-297; P. REDón, La proyección internacional de la Guardia Civil. Misiones de Paz, Barcelona, 1999, págs. 7-8.

105 Además, las elecciones para formar parte del Consejo Asesor de la Guardia Civil se realizaron por procedimientos electrónicos, habiéndoles entregado previamente a los 73.000 miembros de la Guardia Civil la firma electrónica.

106 Como es sabido, los Guardias Civiles no pueden sindicarse. No obstante, existe la Asociación Unificada de la Guardia Civil -AUGC - con cerca de 20.000 afiliados. 
ciones. Sólo esta proverbial combinación de adaptación a las circunstancias y de fidelidad a si misma explica que una Institución como la Guardia Civil haya logrado sobrevivir a la convulsa historia de España de los últimos cincuenta años» 107 .

Así, se puede decir que la Guardia Civil se mueve. Desde el interior de la institución muchas veces esto no se ve y parece que está quieta, que no cambia, que no se mueve. Sin embargo, parafraseando a Galileo se puede decir eppure si muove. La Guardia Civil se mueve y se mueve en una buena dirección.

107 Cfr. S. López Valdivielso, "Prólogo" a I. Cosidó (coord.), La Guardia Civil más allá del año 2000, cit, págs. 9-10. Cfr. también I. Cosıdó, “La Guardia Civil de 2025", Cuadernos de la Guardia Civil, núm. 27, 2002, págs. 19-32. Una reflexión semejante se puede leer en EI País, “La Guardia Civil se destapa”, 23 de febrero de 2003, pág. 67. 